IIIIIIIIIIIIIIIIII

\title{
Review
}

IIIIIIIIIIIIIIIIII

\section{The invertebrate pharmacology of insecticides acting at nicotinic acetylcholine receptors}

\author{
Andrew J. Crossthwaite, ${ }^{1, *}$ Aurelien Bigot, ${ }^{2}$ Philippe Camblin, ${ }^{3}$ Jim Goodchild, ${ }^{1}$ \\ Robert J. Lind, ${ }^{1}$ Russell Slater ${ }^{3}$ and Peter Maienfisch ${ }^{3, *}$ \\ ${ }^{1}$ Syngenta Crop Protection, Jealott's Hill International Research Centre, Bracknell, Berkshire, RG42 6EY, UK \\ ${ }^{2}$ Syngenta Crop Protection AG, Schaffhauserstrasse 101, CH-4332 Stein, Switzerland \\ ${ }^{3}$ Syngenta Crop Protection AG, Schwarzwaldallee 215, CH-4002 Basel, Switzerland
}

(Received March 9, 2017; Accepted June 19, 2017)

\begin{abstract}
The nicotinic acetylcholine receptor ( $\mathrm{nAChR}$ ) is a ligand-gated ion channel composed of 5 protein subunits arranged around a central cation selective pore. Several classes of natural and synthetic insecticides mediate their effect through interacting at nAChRs. This review examines the basic pharmacology of the neonicotinoids and related chemistry, with an emphasis on sapfeeding insects from the order Hemiptera, the principle pest target for such insecticides. Although the receptor subunit stoichiometry for endogenous invertebrate nAChRs is unknown, there is clear evidence for the existence of distinct neonicotinoid binding sites in native insect preparations, which reflects the predicted wide repertoire of nAChRs and differing pharmacology within this insecticide class. The spinosyns are principally used to control chewing pests such as Lepidoptera, whilst nereistoxin analogues are used on pests of rice and vegetables through contact and systemic action, the pharmacology of both these insecticides is unique and different to that of the neonicotinoids. () Pesticide Science Society of Japan
\end{abstract}

Keywords: neonicotinoid, imidacloprid, thiamethoxam, sulfoxaflor, spinosyn, aphid.

\section{Introduction}

Today's global market for insecticides is valued at $\$ 18,619$ million. The most important chemical classes are neonicotinoids (mode of action: modulators of nAChRs; market share: 18.0\% of the total market), pyrethroids (modulators of voltage-gated sodium channels; 17.0\%), organophosphates (inhibition of acetylcholinesterase; 15.3\%), carbamates (inhibition of acetylcholinesterase; $6.7 \%)$, fermentation products (6.7\%) and several other chemical classes having less than 5\% market share each (Fig. 1). ${ }^{1)}$

The insecticides for which the primary target protein is the $\mathrm{nAChR}$ are currently the most commercially successful class reaching total sales of $\$ 4028$ million in 2014 with neonicotionoids contributing $\$ 3345$ million (83.0\%), spinosyns $\$ 533$ million (13.3\%) and neireistoxin analogues $\$ 150$ million (3.7\%) to the total sale (Fig. 1). In 2014 inhibitors of acetylcholinesterase (carbamates and organophosphates) still had a market share of $22.0 \%$ ( $\$ 4091$ million), slightly above the share of

\footnotetext{
* To whom correspondence should be addressed.

E-mail: andrew.crossthwaite@syngenta.com, peter.maienfisch@syngenta.com

Published online July 29, 2017

(c) Pesticide Science Society of Japan
}

nAChR targetting molecules (21.6\%; \$4028 million). However, it can be expected that due to the increasing emergence of resistance and the poor intrinsic selectivity of carbamates and organophosphates for insect acetylcholinesterase over the mammalian form, their use will continue to decline whilst that of nAChR targeting insecticides, particularly neonicotinoids which display excellent insect to mammalian selectivity, will continue to rise.

Among the compounds targeting the nAChRs, thiamethoxam (sales 2014: $\$ 1180 \mathrm{~m})$ and imidacloprid $(\$ 1160 \mathrm{~m})$ are the leading products, followed by clothianidin $(\$ 460 \mathrm{~m})$, spinosad $(\$ 310 \mathrm{~m})$, acetamiprid $(\$ 270 \mathrm{~m})$, spinetoram $(\$ 220 \mathrm{~m})$, thiacloprid $(\$ 150 \mathrm{~m})$ and cartap $(\$ 140 \mathrm{~m})$. All other commercial products primarily acting at this target represent lower market shares and only reached together sales of $\$ 138$ million in 2014 (Fig. 2).

The success of the systemically delivered neonicotinoids is due to their wide range of use in controlling hemipteran sapfeeding insects (e.g. aphids, whiteflies, hoppers, scales etc.), foliar feeding insects (e.g. Colorado potato beetle, diamond back moth $e t c$.) and via seed treatment against a range of soil pests (e.g. corn rootworm, white grubs, wireworms etc.). ${ }^{2}$ Despite a heavy reliance on this class of insecticide chemistry in many agricultural systems, the neonicotinoids have proven to be relatively robust to insecticide resistance development, with only a few significant cases of resistance development documented over the last 19 years. ${ }^{3,4)}$ In all cases, resistance can be associated with 


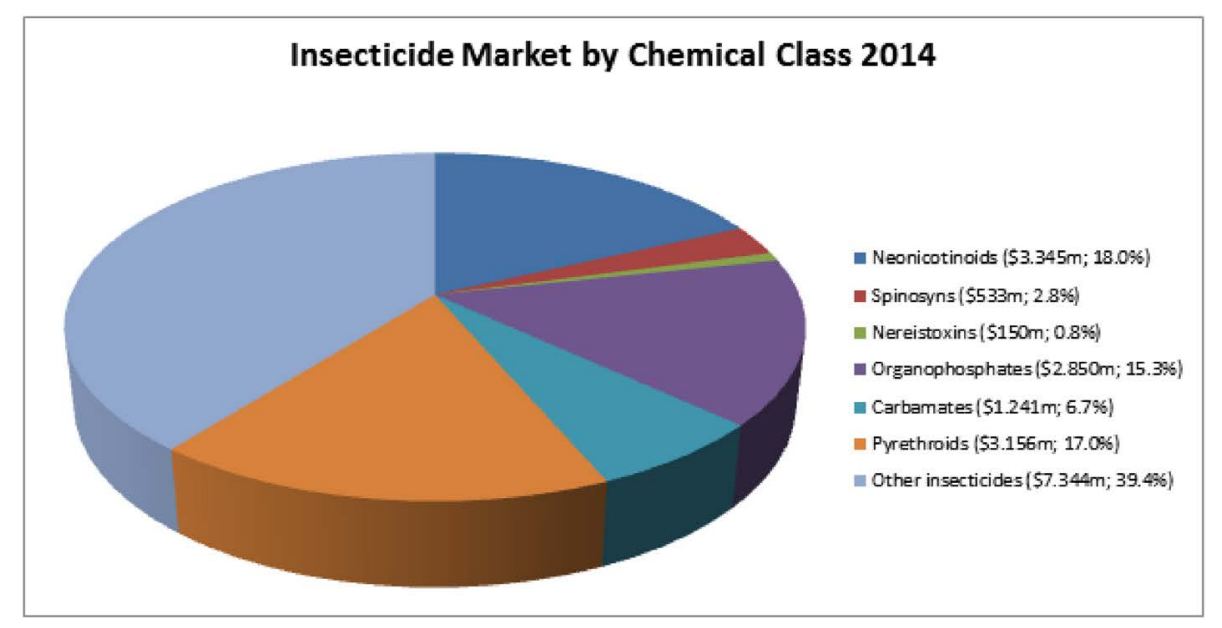

Fig. 1. Insecticide market by chemical class.

the poor implementation of rotation management practices as recommended by the Insecticide Resistance Action Committee (IRAC). ${ }^{2,3,5-10)}$

The spinosyns (spinosad and spinoteram) are used principally to control chewing pests, for example leafminers, but also display efficacy against certain cell-feeding insects such as thrips. The nereistoxins are a niche market product used for controlling certain pests in rice, vegetables and potatoes.

The development of resistance, the mounting global regulatory pressure leading to the dwindling of insecticide mode of action classes combined with the necessary rise in global food production capacity required to feed the growing global population, are key drivers for continued innovation in crop protection. Considering the broad pest spectrum, applicability to various cropping systems and systemicity potential, agribusiness companies are still searching for new nAChR modulating chemistry with favourable characteristics to address issues with the current commercial neonicotinoids. Indeed, in the last few years three new nicotinic modulating insecticides have been launched. Sulfoxaflor, a novel sulfoximine insecticide reached the market in 2012, flupyradifurone, a novel butenolide pharmacophore launched in 2014 and most recently, triflumezopyrim, a new class of mesoioinc insecticide. All compounds display excellent activity on their target pests including those with metabolismbased resistance to conventional neonicotinoids. ${ }^{11)}$ Further examples, especially from Chinese companies for their domestic market are currently in late development or early market introduction. ${ }^{12)}$ Therefore the $\mathrm{nAChR}$ remains an extremely important target for invertebrate research.

\section{Invertebrate nicotinic acetylcholine receptors}

The nAChRs are a member of the "Cys-loop" super-family of pentameric ligand gated ion channels. ${ }^{1)}$ The receptor is a homoor a hetero-pentamer of related subunits arranged around a central cation selective pore. Each subunit has a large extracellular N-terminal domain that contains the acetylcholine (ACh) binding site, 4 transmembrane domains (TMD) and an enlarged intracellular loop between TMD3 and 4, containing sites for channel modification via phosphorylation. ${ }^{14,15)}$ The vertebrate nAChRs possess up to five binding sites lying at the interface

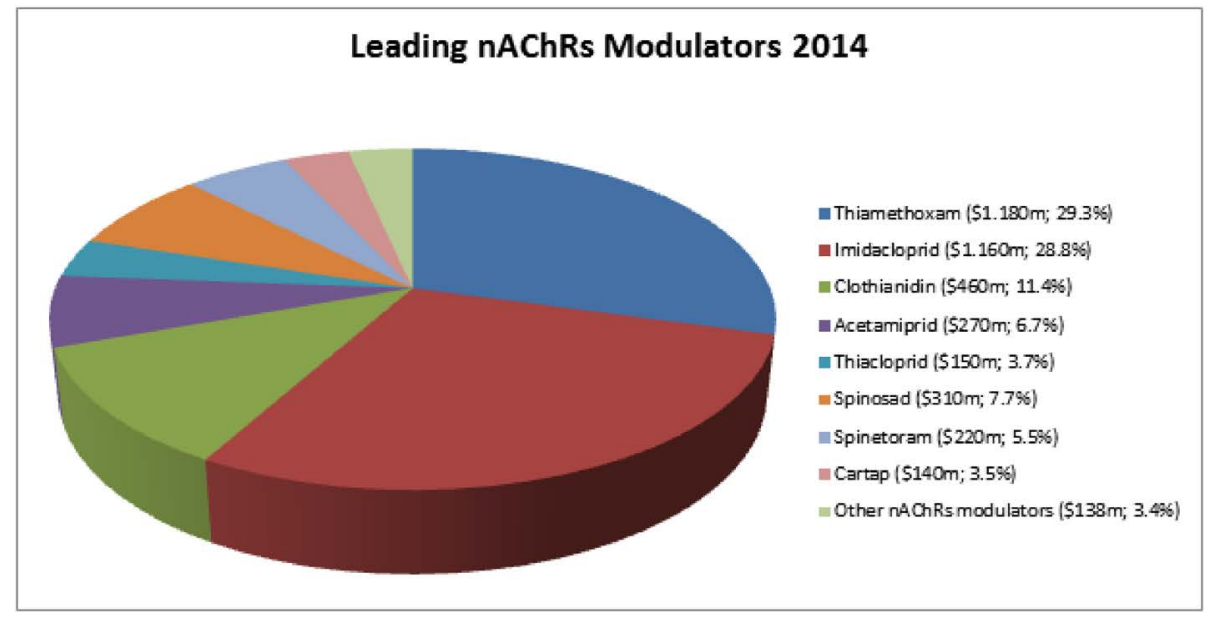

Fig. 2. 2014 Sales of leading $n A C h R$ modulators (neonicotinoids, spinosyns and nereistoxin analogues). 


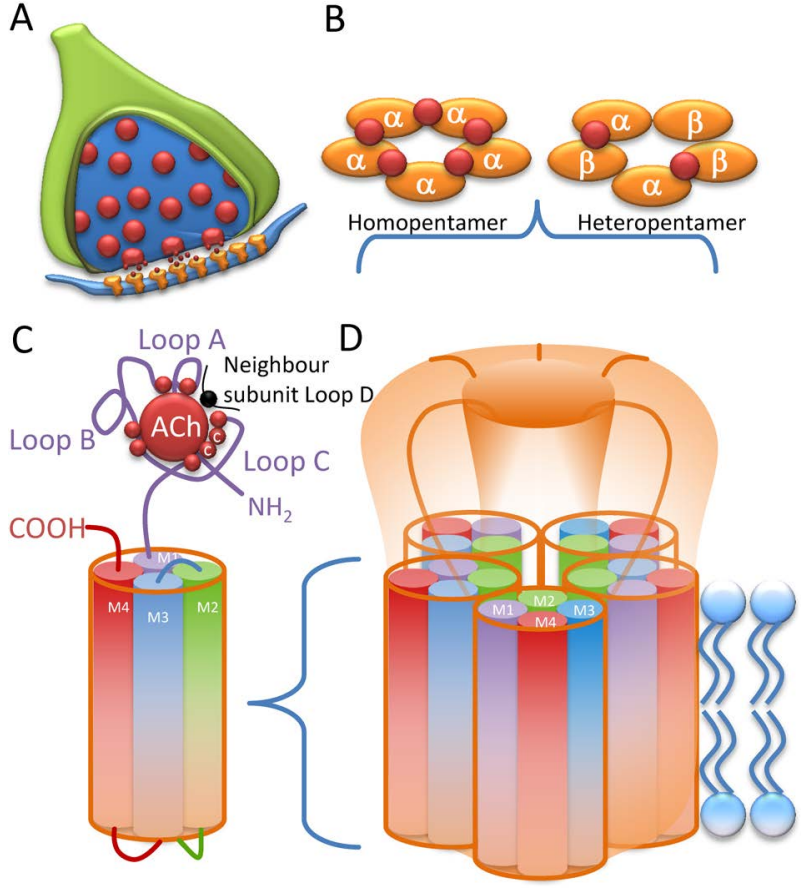

Fig. 3. The Nicotinic acetylcholine receptor. (A) The nAChR is an integral membrane protein embedded in the post synaptic membrane. (B) The $\alpha$ and $\beta$ subunits are arranged in a homo or hetero-pentameric structure, with the ACh binding site lying at the interface between subunits, as denoted in red. (C) Each subunit has a large N-terminus, 4 transmembrane domains and a large intracellular loop. The ACh binding site is made up of 3 loops from the principal $\alpha$-subunit and contact point from the $\beta$-subunit of the M1 domain. The position of the cysteine amino acids that form the critical disulphide loop are shown. (D) A functional nAChR contains five subunits with the second transmembrane domain lining the pore of the channel.

between an $\alpha$-subunit and either another $\alpha$-subunit in its homopentameric form or a different $\alpha$ or complementary $\beta$-subunit in its heteropentameric form. ${ }^{16-18)}$ A similar arrangement for the agonist binding site in the invertebrate nAChR is also postulated, although the exact subunit composition of functional insect $\mathrm{nAChRs}$ remains unknown. ${ }^{19)}$ Unlike verterbrate nAChRs, heterologous expression of genuine heteropentameric ( $\alpha$ and $\beta$ subunit combinations) insect $\mathrm{nAChRs}$ has not been successful, although heteropentameric receptors composed of mixed $\alpha$ subunits has been achieved. ${ }^{20)}$ As of yet no laboratory has successfully expressed an insect $\beta$ subunit that participates in a functional ion channel, however insect $\alpha$ subunits will form heteropentameric channels with mammalian/avian $\beta$ subunits (Fig. 3). ${ }^{21,22)}$ The reasons behind this are not well understood but the correct combination of $\mathrm{nAChR}$ subunits with corresponding chaperone proteins in the adequate cellular background may be required to form the functional receptor. Therefore, to date, knowledge on insect nAChR pharmacology has been principally derived from radioligand binding studies on native insect homogenates combined with direct electrophysiological recordings from exposed/isolated nervous tissue and heterologous expression studies with co-expressed mammalian/avian $\beta$ subunits.
Insect genome sequencing projects have allowed the complete identification of $\mathrm{nAChR}$ gene families, for example Drosophila melanogaster (fruit fly), ${ }^{23)}$ Anopheles gambiae (malaria mosquito), ${ }^{24)}$ Apis mellifera (honey bee), ${ }^{25)}$ Tribolium castaneum (red flour beetle) ${ }^{26)}$ and Acyrthosiphon pisum (pea aphid). ${ }^{27)}$ The described insects have between 10-12 nAChR genes, whilst birds and mammals have 17 and Caenorhabditis elegans has at least $27 .^{28,29)}$ Insects have a "core-group" of related nAChR genes that display $60 \%$ or greater homology between species, additionally there are species specific genes which typically display less than $20 \%$ sequence identity. Of particular relevance to neonicotinoid use is the genomic annotation of A. pisum which possesses 11 $\mathrm{nAChR}$ genes in total, eight of which fall into the core-group, although there is no $D$. melanogaster $\alpha 5$ orthologue. There are three pea aphid specific genes, namely $\alpha 9, \alpha 10$ and $\beta 2$, of which $\alpha 9$ and $\alpha 10$ are without the characteristic "Cys-loop" that forms the disulphide bridge implicated in receptor assembly and function $^{30,31)}$ (Fig. 3). Instead one of the cysteines is replaced by a glycine residue, so the disulphide bridge cannot form in these subunits. Receptors containing this cysteine alteration in a subunit may form functional channels but will clearly display unique properties. ${ }^{32)}$ Although insects display a smaller nAChR gene pool compared to other species, alternative splicing and RNA editing suggest a plethora of different $n A C h R$ receptors can be expected across the nervous system with clear opportunities for species specific subunit combinations. ${ }^{33)}$ In recent years there has been a lot of research and media attention on the interaction of neonicotinoids with pollinator insects. Given the challenge of understanding realistic exposure doses for pollinators under field conditions of use, alongside the complexities of interpreting receptor level changes to effects on individuals, different pollinator species and even different populations, this is out of scope for the review. Instead the reader is referred to recent articles. ${ }^{34,35)}$ The focus of this review will be to examine the principal $\mathrm{nAChR}$ modulating insecticides and their invertebrate receptor pharmacology, the evidence of which strongly implies differential nAChR targeting.

\section{2. nAChR orthosteric modulators}

Orthosteric modulators of the nAChRs are the most successful new insecticidal class and commonly referred to as neonicotinoids. The term neonicotinoid was originally introduced by Izuru Yamamoto $^{36,37)}$ for imidacloprid, the first-in-class molecule discovered by Shinzo Kagabu ${ }^{38)}$ and for related analogues which followed this breakthrough invention and represent the IRAC group 4A. ${ }^{39)}$ The term aimed at differentiating these new insecticides based on their unique structural and pharmacophoric features compared to the nicotinoids (a term also suggested by Yamamoto back in the 1960s) ${ }^{40)}$ which are likewise nAChR orthosteric modulators yet containing a key basic nitrogen and structurally related to nicotine (for instance epibatidine, cytisine, anatoxin). ${ }^{41)}$ Imidacloprid was actually not discovered from natural alkaloids but from synthetic nitromethylene heterocycles (Fig. 4). ${ }^{42)}$ Electrophysiological studies performed on the 


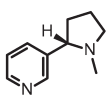

nicotine
Fig. 4. Historical development of imidacloprid.

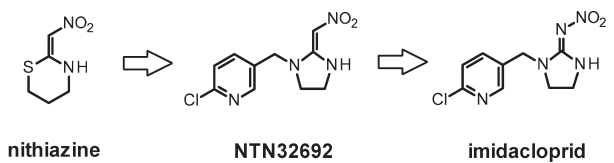

Shell lead nithiazine established its agonistic activation of insect $n \mathrm{AChRs}^{43)}$ and subsequent chemical optimization through synthetic derivatization led to the discovery of imidacloprid in 1985. ${ }^{44-46)}$ The key introduction of the 6-chloro-pyridylmethyl to a nitroenamine analogue of nithiazine resulted in a dramatic increase of the biological activity and defined the chloronicotinyl first generation of neonicotinoids.

Indeed the discovery of imidacloprid triggered extensive research programs within several other agrochemical companies leading to the development of further chloronicotinyl neonicotinoids and next generation neonicotinoids (Fig. 5). Nitenpyram (Takeda now Sumitomo, 1995) ${ }^{47)}$ was the first acyclic neonicotinoid bearing a nitroenamine to reach the market followed by acetamiprid (Nippon Soda, 1996) ${ }^{48)}$ featuring a novel cyanoamidine pharmacophore and thiacloprid (Bayer CropScience, $2000){ }^{49)}$ incorporating this latter motif in a ring with an additional sulfur atom. Thiamethoxam (Syngenta, 1998) ${ }^{50)}$ was the first neonicotinoid introducing a chlorothiazolyl as bioisosteric replacement of the chloropyridyl aromatic heterocycle. It is attached to a unique oxadiazine six-membered ring embedding a $\mathrm{N}$-methyl nitroguanidine pharmacophore. Clothianidin (Bayer CropScience, 2002) ${ }^{51)}$ followed as an acyclic analogue and dinotefuran (Mitsui 2002) ${ }^{52)}$ retains the acyclic nitroguanidine pharmacophore but branches an unprecedented tetrahydrofuranyl saturated heterocycle. Sulfoxaflor is the first example of a sulfoximine nicotinic agonist (Dow Agrosciences 2012), ${ }^{53}$ ) flupyradifurone introduces a butenolide pharmacophore (Bayer CropScience 2014) ${ }^{54)}$ and the latest molecule entering the marketplace, triflumezopyrim features a mesoionic heterocycle (DuPont 2015) ${ }^{55)}$ as novel sucking pest solutions.

Sulfoximines, butenolides and mesoionics (see chapter 2.7.1) are all novel chemistry classes modulating insect nAChRs with representative compounds recently introduced on the market. This increases the chemical diversity and complexity of insecticides acting at the ACh binding site of nAChRs. Despite their structural differences which can be subtle to drastic, all current

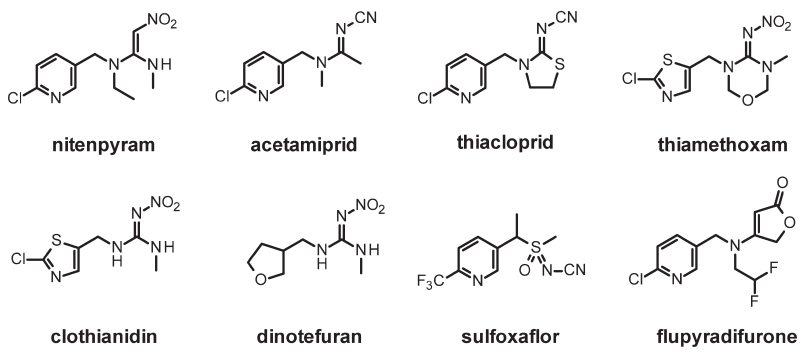

Fig. 5. Other commercialized $n A C h R$ agonists. and near-term anticipated commercial orthosteric modulators share crucial pharmacophoric features which account for their affinity and insect selectivity. These structural aspects have been discussed elsewhere and are beyond the scope of this review. ${ }^{56,57)}$ The purpose of this manuscript is to examine the invertebrate pharmacology of all commercialized insecticides that mediate their action through modulation of nAChRs. Additionally, given the increasing chemical diversity of orthosteric modulators we identify updated criteria for defining the neonicotinoids as originally introduced by Yamamoto, ${ }^{37)}$ specifically in relation to mode of action.

\subsection{Chloronicotinyl compounds}

\subsubsection{Imidacloprid-Pharmacological nature of binding}

Imidacloprid (IMI), containing a nitroguanidine pharmacophore, represents the prototypical neonicotinoid and is the most extensively investigated neonicotinoid to date. Radiolabel studies have demonstrated that tritiated IMI $\left(\left[{ }^{3} \mathrm{H}\right]-\mathrm{IMI}\right)$ binds with nanomolar affinity to $\mathrm{nAChRs}$ in insect tissue and the structure activity relationship for displacement by closely related analogues correlates with insecticidal potency, providing a direct link between receptor affinity and invertebrate toxicity. ${ }^{58-60)}$ The commercial chloropyridyl neonicotinoids all displace $\left[{ }^{3} \mathrm{H}\right]-\mathrm{IMI}$ binding with high potency (low $\mathrm{nM} K_{\mathrm{i}}$ ), implying that chloropyridyl neonicotinoids share common $\mathrm{nAChR}$ target(s) site(s). The non-chloropyridyl neonicotinoids vary in their pharmacological profile with respect to IMI and are discussed in subsequent sections. The early studies on neonicotinoids made use of radiolabelled $\alpha$-bungarotoxin ( $\alpha$-BGTX), since it was commercially available, highly specific for nAChRs and used extensively within mammalian $\mathrm{nAChR}$ investigations. However, a common feature in binding studies investigating the relationship between $\alpha$-BGTX and IMI is that the binding sites display different properties. Indeed, the $\mathrm{IC}_{50}$ comparative correlation for displacement potency of neonicotinoids between $\left[{ }^{3} \mathrm{H}\right]$-IMI and radiolabelled $\alpha$-BGTX is only weak. ${ }^{61-63)}$ Taken together this body of evidence has led to the suggestion that IMI and $\alpha$-BGTX have distinct high affinity binding sites. ${ }^{64,65)}$ Therefore, studies investigating neonicotinoid potency using displacement values derived from radiolabeled $\alpha$-BGTX studies are of limited value and should be interpreted with extreme care.

The exact nature of IMI binding to invertebrate nAChRs is unclear. Both high and low affinity $\left[{ }^{3} \mathrm{H}\right]$-IMI binding sites at the nAChRs are observed in Musca domestica (house fly). ${ }^{66)} \mathrm{A}$ detailed comparison of $\left[{ }^{3} \mathrm{H}\right]$-IMI binding in different insect species was carried out by Lind et al. ${ }^{62)}$ An interesting observation was that Myzus persicae (peach potato aphid) and Nephotettix cincticeps (green leaf hopper), both hemipteran sap-feeding insects, displayed two binding sites, a very high affinity binding site with a sub-nM $K_{\mathrm{d}}$, as well as a further lower affinity binding site having low $\mathrm{nM}$ affinity. The sub-nM $K_{\mathrm{d}}$ affinity site was absent in the other insect species (non-hemipteran) investigated; Periplaneta americana (American cockroach), Lucilia sericata (blow fly), D. melanogaster (fruit fly), Manduca sexta (tobacco 
hornworm), Heliothis virescens (tobacco budworm) and Ctenocephalides felis (cat flea). This intriguing observation was suggested to explain why IMI is particularly useful for controlling sap-feeding insects. A separate detailed study in M. persicae and Aphis craccivora (cow pea aphid) confirmed this observation. ${ }^{67}$ However, in this study, the presence of a very high affinity binding site in neuronal tissue from Locusta migratoria (migratory locust) was also found. More recently, the presence of dual affinity binding sites for $\left[{ }^{3} \mathrm{H}\right]$-IMI has also been observed in another hemipteran species, Nilaparvarta lugens (brown plant hopper) further solidifying the argument that hemipteran pests have two binding sites. ${ }^{68,69)}$ Certainly, not all studies on hemipteran pests have identified dual binding sites and this is likely to be down to the difficult nature of the experiments to tease out the very high affinity but low abundance site, as well as differences in interpretation of the data. ${ }^{67,70)}$ However, a general trend appears to be that when low \% Triton X-100 is included in incubations the duality of binding disappears and only a single binding site (low $\mathrm{nM} K_{\mathrm{d}}$ ) is observed in aphid and fly species. ${ }^{66,71)}$ The effects of including detergent are complex and not easily rationalised but low $\mu \mathrm{M}$ concentrations of Triton may interfere with $\left[{ }^{3} \mathrm{H}\right]-\mathrm{IMI}$ binding. ${ }^{62,65)}$ It has been suggested that two sites for IMI binding maybe the norm, but this certainly requires further evidence for insects outside of the hemipteran order. ${ }^{67,71,72)}$

Strengthening the idea that hemipteran neonicotinoidresponsive nAChRs display differences compared to other insect orders, Casida applied a photoaffinity-based approach using an azido non-cyclic $\mathrm{N}$-methyl derivative of IMI and demonstrated that the nAChR subunits isolated differed significantly in molecular weight between hemipteran and dipteran insects. ${ }^{73,74)}$ The subunits required to form the two distinct IMI binding sites in a hemipteran pest have been reported. Adopting an immunoprecipitation based approach with subunit specific polyclonal antibodies on detergent solubilised $N$. lugens membranes, the very high affinity binding site is proposed to be composed of $\mathrm{Nl} \alpha 3, \mathrm{Nl} \alpha 8$ and $\mathrm{Nl} \beta 1$ whilst the lower affinity IMI binding site is reportedly composed of $\mathrm{Nl} \alpha 1, \mathrm{Nl} \alpha 2$ and $\mathrm{Nl} \beta 1{ }^{75)}$ Furthermore the use of antibodies targeted at specific subunits revealed that immunodepletion of either $\mathrm{Nl} \alpha 3$ or $\mathrm{Nl} \alpha 8$ resulted in loss of the very high affinity site whilst immunodepletion of $\mathrm{Nl} \alpha 1$ or $\mathrm{Nl} \alpha 2$ eliminated the lower affinity IMI binding site. It therefore seems likely that the presence of two IMI binding sites in hemiptera might be explained by distinct populations of receptors rather than differential IMI affinity at sites within the same nAChR. This study by Li et al. is the first demonstration of native insect $\mathrm{nAChR}$ subunit combinations that underlie differential IMI binding affinities, however the stoichiometry for subunit arrangement is not yet known. It will be of interest to examine whether this is a species specific observation, as high and low affinity binding sites for IMI have not been resolved in all insect species. ${ }^{62)}$ Even for highly related subunits between Hemiptera and Diptera species, pharmacological differences to IMI are observed. The $\operatorname{Mp} \alpha 1$ and $\operatorname{Dm} \alpha 2$ subunits share $94 \%$ amino acid sequence in the N-terminal (which contains the agonist bind- ing domain), however whereas Dm $\alpha 2$ interacts with IMI, Mp $\alpha 1$ does not. ${ }^{76,77)}$ Therefore, the weight of evidence clearly implies that hemipteran insects display unique neonicotinoid pharmacology when compared to other insect orders.

An enhancement on the understanding of the nature of IMI interaction with the $\mathrm{nAChR}$ in hemipteran pests and its relationship to toxicity was derived from a resistance-based approach. Laboratory pressurising of $N$. lugens with IMI over 35 generations resulted in a 250 fold level of resistance. Subsequent cloning of $\mathrm{nAChR} \mathrm{Nl} \alpha$-subunits revealed several polymorphisms but only one associated with high level IMI resistance, the replacement of tyrosine at position 151 to a serine in both $\mathrm{Nl} \alpha 1$ and $\mathrm{Nl} \alpha 3$. It is of interest to note that homozygotes with mutations in both $\mathrm{Nl} \alpha$ subunits were required for very high level resistance. Heterozygous N. lugens displayed a lower level of resistance, suggesting that the Y151S mutation is required in two separate nAChR genes for high level resistance to occur. ${ }^{68)}$ Correlating this observation with the findings in N. Lugens that the high and low affinity $\left[{ }^{3} \mathrm{H}\right]-\mathrm{IMI}$ binding sites contain $\mathrm{Nl} \alpha 3$ and $\mathrm{Nl} \alpha 1$ respectively, this suggests that a mutation in both binding sites is required to achieve high level resistance (it should be noted no investigations were performed on these insects to understand whether any non-target site alterations contributed to resistance. For example, the susceptible and resistant strains were not back-crossed to near isogenicity). The presence of the Y151S mutation did not affect total nAChR receptor expression levels, either in membranes from $N$. lugens or when expressed heterologously in cells (co-expressed with rat $\beta$-subunits). However Y151S significantly reduces the specific binding of $\left[{ }^{3} \mathrm{H}\right]$ IMI, as well as reducing IMI agonist activity in co-expressing systems. $^{78-80)}$ The Y151 amino acid is highly conserved between insects and mammals, so itself is not thought to be directly involved in IMI binding, rather the presence of the serine may induce a conformational change within the binding site rendering it less favourable to interaction. ${ }^{68,81)}$ The proposed effect of the Y151S on neonicotinoid binding to insect nAChRs has recently been modelled using the crystal structures of Lymnaea stagnalisACh binding protein (Ls-AchBP) in complex with IMI. ${ }^{56)}$

\subsubsection{Field-evolved imidacloprid target-site resistance}

Of more relevance to commercial use of neonicotinoids are field evolved mutations in the nAChR associated with high level resistance which have been identified in two distinct aphid species. The first reported case was a strain of $M$. persicae, clone FRC, isolated from peach orchards in South France which has a single point mutation in the loop $\mathrm{D}$ region of the $\mathrm{nAChR} \beta 1$ subunit, causing an arginine to threonine substitution (R81T). ${ }^{3)}$ An analogous R81T mutation has also been observed in the Kushima clone of Aphis gossypii from Japan. ${ }^{82)}$ The same mutation had been identified in Chinese strain of A. gossypii, although this was isolated through IMI-selection pressure for 60 generations in the laboratory environment. ${ }^{83,84)}$ In addition the insensitivity of ticks to neonicotinoids is now known to be due to the presence of glutamine rather than arginine at position $81 .^{85)}$ The R81T mutation confers a vertebrate-like character to 
Table 1. Invertebrate $\left[{ }^{3} \mathrm{H}\right]$-IMI radioligand summary $\left[K_{\mathrm{d}}(\mathrm{nM})\right.$, Hill value and $\left.B_{\max }(\mathrm{fmol} / \mathrm{mg})\right]$.

\begin{tabular}{|c|c|c|c|c|c|}
\hline Pest & Species & $K_{\mathrm{d}}(\mathrm{nM})$ & $B_{\max }(\mathrm{fmol} / \mathrm{mg})$ & $\mathrm{nH}^{a)}$ & Reference \\
\hline \multirow[t]{19}{*}{ Hemipteran } & \multirow[t]{9}{*}{ Myzus persicae } & 0.14 & 284 & \multirow[t]{2}{*}{0.61} & \multirow[t]{2}{*}{51} \\
\hline & & 12.58 & 486 & & \\
\hline & & 0.85 & 65 & \multirow[t]{2}{*}{0.75} & \multirow[t]{2}{*}{60} \\
\hline & & 7 & 260 & & \\
\hline & & 0.6 & 250 & \multirow[t]{2}{*}{0.85} & \multirow[t]{2}{*}{56} \\
\hline & & 7.2 & 716 & & \\
\hline & & 0.083 & 100 & \multirow[t]{2}{*}{0.78} & \multirow[t]{2}{*}{11} \\
\hline & & 1.7 & 298 & & \\
\hline & & 2.3 & 220 & $1^{b)}$ & 60 \\
\hline & Myzus persicae FRC & 4.14 & 2016 & 1 & 11 \\
\hline & \multirow[t]{5}{*}{ Aphis craccivora } & 0.8 & 226 & \multirow[t]{2}{*}{0.77} & \multirow[t]{2}{*}{56} \\
\hline & & 21 & 911 & & \\
\hline & & $0.4-1.6$ & $45-97$ & $0.65-0.75$ & 60 \\
\hline & & $7-15$ & $96-156$ & & \\
\hline & & 2.2 & 86 & $0.97^{b)}$ & 60 \\
\hline & \multirow[t]{2}{*}{ Nephotettix cincticeps } & 0.0043 & 33 & \multirow[t]{2}{*}{0.67} & \multirow[t]{2}{*}{51} \\
\hline & & 1.23 & 179 & & \\
\hline & \multirow[t]{2}{*}{ Nilaparvata lugens } & 0.0035 & 4.1 & \multirow[t]{2}{*}{ not reported. } & \multirow[t]{2}{*}{64} \\
\hline & & 1.5 & 18.3 & & \\
\hline \multirow[t]{16}{*}{ Non-hemipteran } & Periplaneta americana & 3.14 & 2140 & $1.01^{c)}$ & 51 \\
\hline & Lucilia sericata & 1.75 & 539 & $1.02^{d)}$ & 51 \\
\hline & \multirow[t]{4}{*}{ Drosophila melanogaster } & 1.42 & 126 & 1.04 & 51 \\
\hline & & 2.2 & 1344 & $1.02^{d)}$ & 60 \\
\hline & & 2.5 & 1621 & $1^{b, d)}$ & 60 \\
\hline & & 2.4 & 560 & $0.99^{b, d)}$ & 62 \\
\hline & \multirow[t]{5}{*}{ Musca domestica } & 0.7 & 305 & \multirow[t]{2}{*}{$0.84^{d)}$} & \multirow[t]{2}{*}{55} \\
\hline & & 9 & 475 & & \\
\hline & & 5.4 & 428 & $98^{d)}$ & 60 \\
\hline & & 3.2 & 400 & $1.01^{b, d)}$ & 60 \\
\hline & & 1.2 & 853 & $0.99^{b, d)}$ & 49 \\
\hline & Manduca sexta & 1.3 & 150 & $0.99^{e)}$ & 51 \\
\hline & Heliothis virescens & 1.51 & 134 & $0.92^{f}$ & 51 \\
\hline & Ctenocephalides felis & 4.82 & 369 & 0.95 & 51 \\
\hline & \multirow[t]{2}{*}{ Locusta migratoria } & 0.2 & 153 & \multirow[t]{2}{*}{$0.63^{g)}$} & \multirow[t]{2}{*}{56} \\
\hline & & 8.9 & 336 & & \\
\hline
\end{tabular}

${ }^{a)}$ Whole body unless noted. ${ }^{b)}$ Performed in the presence of Triton X-100. ${ }^{c}$ Head dissection, ${ }^{d)}$ head enrichment, ${ }^{e}$ enriched brain, ${ }^{f)}$ adult isolated head region and, ${ }^{g}$ head and thorax ganglia.

the $\alpha 1$ subunit rendering it less favourable to interact with the electronegative domain of neonicotinoids. ${ }^{3,56,81)}$ Indeed, the FRC M. persicae strain has high level resistance to all commercialised neonicotinoids. ${ }^{4)}$ Interestingly, the dual nature of $\left[{ }^{3} \mathrm{H}\right]$-IMI binding observed in wildtype aphids (as described above) is dramatically altered in FRC. The highest affinity site is completely absent in FRC and instead only a single $\left[{ }^{3} \mathrm{H}\right]$-IMI binding site is present. This single site has a reduced affinity to $\left[{ }^{3} \mathrm{H}\right]$-IMI compared to the second lower affinity site in wildtype aphids (Table 1).
Given the above observations in $N$. lugens that the $\beta 1$ subunit is an essential component in the separate $\mathrm{nAChR}$ populations deriving both the high and lower affinity $\left[{ }^{3} \mathrm{H}\right]$-IMI binding sites, it is perhaps not surprising that the nature of $\left[{ }^{3} \mathrm{H}\right]$-IMI binding in FRC is completely different to susceptible strains. The nAChR subunit stoichiometry of the single [ $\left.{ }^{3} \mathrm{H}\right]$-IMI binding site in FRC is unknown, even whether it contains the mutated $\beta 1$ or if this has been replaced, for example by the $\beta 2$ subunit. Much remains to be explained and investigated with this clone of aphid, which 
will of no doubt be an extremely useful tool in aiding understanding of nAChR pharmacology in hemipteran insects.

2.1.3. Imidacloprid-Functional activity at the nicotinic acetylcholine receptor

IMI is essentially a partial agonist of insect nAChRs but its efficacy can vary depending on the nerve preparation in question. ${ }^{86,87)}$ The diversity of neuronal responses is likely to be due to the actions of IMI on nAChRs of differing quaternary structure, which vary in their kinetic properties and their allosteric response to IMI binding. IMI was found to be only a partial agonist of nAChRs in cockroach neurones, ${ }^{88)}$ honeybee Kenyon cells, ${ }^{89)}$ and in cultured D. melanogaster neurones. ${ }^{86,90)}$ In heterologous receptors derived from co-expression of $N$. lugens $\alpha$-subunits with rat $\beta 2$ subunit, IMI is converted to an antagonist by a Y $151 \mathrm{M}$ point mutation in the $\mathrm{Nl} \alpha 1$ subunit, indicating that single amino-acid changes can impart significant changes in the channel response to IMI. ${ }^{91)}$ Recent electrophysiology results on avian homopentamer $\alpha 7$ mutated with key insect-specific amino acids S58K and Q79R showed an enhanced efficacy in terms of maximum current $\left(I_{\max }\right)$ compared to wild-type as well as a higher $\mathrm{pEC}_{50}$, pointing out the importance of the insect specific basic residues impacting not only the affinity but also potentially the functional activity of IMI at insect nAChRs. ${ }^{92)}$

The selectivity of IMI for different populations of nAChRs is evident from electrophysiological recordings of isolated $P$. americana thoracic ganglia neurons. These neurones possess two pharmacologically distinct components to the nAChR current initiated by $\mathrm{ACh}$ application: an initial rapidly desensitising current (nAChD) that peaks within a few hundred milliseconds which is completely blocked by nanomolar application of IMI and a prolonged non-desensitising current (nAChN) which is selectively blocked at sub-nanomolar concentrations by the nAChR antagonist methyllycaconitine (MLA) but activated by micromolar concentrations of IMI. ${ }^{65)}$ Therefore, the concentration of IMI at the receptor will have a strong influence on the overall neuronal effect, with low nanomolar concentrations appearing to antagonise nAChRs (likely to be more physiologically relevant), whilst rising concentrations cause receptor activation through the stimulation of the $\alpha$-BGTX sensitive non-desensitising population of nAChRs. ${ }^{65,93)}$

The exact mechanism by which IMI exerts its effects on insects is clearly a complex issue but is subject to differences in the binding sites presented by different $\mathrm{nAChR}$ subtypes and the way that occupancy favours particular conformational states of nAChRs. These parameters combined with bioavailability, concentration, distribution and biotransformation (production of active/inactive metabolites) determine delivery of the ultimate pathophysiological effects - anti-feedency and neurotoxicity. ${ }^{94,95)}$

\subsubsection{Acetamiprid and thiacloprid}

Acetamiprid and thiacloprid possess a cyanoamidine pharmacophore. There is little evidence to suggest that the cyano group within acetamiprid or thiacloprid alters the nAChR pharmacology with respect to IMI in pest species. Indeed, both the cyanoamidines are potent at displacing $\left[{ }^{3} \mathrm{H}\right]-\mathrm{IMI}$ and are currently believed to share similar target site(s). ${ }^{96)}$ However, the acyclic $v s$. cyclic configuration may alter the response of the nAChR. Thiacloprid is only a partial agonist of the $\mathrm{nAChR}$ receptor in cockroach neurones, whilst acetamiprid is a much more efficacious agonist. ${ }^{97)}$ The fact that the cyano-amidines are well suited for lepidopteran control is thought to be due to physico-chemical differences rather than any species specific receptor pharmacology. Acetamiprid has a higher $\log P$ than nitroguanidine equivalents and replacing the 3 position in the imidazoline ring with sulphur also increases hydrophobicity (thiacloprid), this is predicted to enhance cuticle penetration and hence lepidopteran contact activity. ${ }^{98)}$

\subsubsection{Nitenpyram}

Nitenpyram is the only commercial neonicotinoid possessing a nitroenamine pharmacophore. Generally, radiolabeled nitromethylene imidazolidine displacement studies have demonstrated that nitroenamines have higher affinity at the nAChRs than their nitroguanidine counterparts. ${ }^{66)}$ An electrophysiological study on verterbrate/invertebrate $\mathrm{nAChR}$ subunits co-expressed in Xenopus oocytes has also highlighted that nitroenamines generally shift the concentration-response curve to lower concentrations, again suggesting that the olefin bond improves potency over the imine bond. ${ }^{99)}$ However, the improved photostability of nitroimino compounds makes them more suited for agrochemical use $\mathrm{e}^{46)}$ and the higher hydrophilicity of nitroimino compounds has been suggested to increase transport to the target site, overcoming their slightly lower intrinsic potency. ${ }^{36,98)}$

\subsection{Thianicotinoyl compounds}

\subsubsection{Clothianidin}

Clothianidin possesses a nitroguanidine pharmacophore as found in IMI. It is a potent displacer of $\left[{ }^{3} \mathrm{H}\right]$-IMI $\left(K_{\mathrm{i}}\right.$ low $\left.n M\right)$, implying that the $\mathrm{nAChR}$ subunit interface does not readily distinguish between chlorothiazolyl/pyridyl chemistry, although the optimal heterocycle for receptor potency depends on the rest of the neonicotinoid structure. ${ }^{46,71)}$ Additionally, in terms of agonist effects at the $\mathrm{nAChR}$, clothianidin does appear to have different properties to IMI. Clothianidin induces a greater maximum response at $\mathrm{nAChRs} \mathrm{compared} \mathrm{to} \mathrm{the} \mathrm{full} \mathrm{agonist} \mathrm{ACh}$ and is referred to as a super-agonist, in contrast to imidacloprid and nicotine which are partial agonists. ${ }^{90,100)}$ It is believed that IMI and ACh bind to a nAChR conformation that favours a lower conductance state whilst clothianidin stabilizes nAChRs in a large conductance state, hence explaining the super-agonism effect in comparison to IMI. The structure-functional activity relationship is though not easily rationalized, for instance a chloropyridyl analogue of clothianidin also displays super agonistic activity whereas other acyclic neonicotinoids such as nitenpyram or dinotefuran do not exert this effect. ${ }^{90,99,100)}$ It has been claimed that the super-agonist effect of clothianidin is responsible for its higher insecticidal activity over IMI, however the effects of super agonism and its relationship to toxicity require further study. 


\subsubsection{Thiamethoxam}

Thiamethoxam (TMX) occupies the current number one position in terms of overall global sales with $>37 \%$ market share of the conventional neonicotinoid market. Despite this, the interaction of TMX with nAChR receptors is arguably less understood than that for the other neonicotinoids. TMX is very weak at displacing $\left[{ }^{3} \mathrm{H}\right]-\mathrm{IMI}$ with a $K_{\mathrm{i}}$ in the $\mu \mathrm{M}$ range, clearly implying a different physiological mechanism of $\mathrm{nAChR}$ interaction to IMI-like neonicotinoids. Indeed, it has been suggested that in insects, cleavage of the oxadiazine residue generates clothianidin and that TMX is a pro-drug of clothianidin. ${ }^{101,102)}$ However, the rate and degree of clothianidin production in vivo from TMX treated insects does not correlate with its rapid toxicological symptoms, suggesting that TMX must be neuroactive in its own right. ${ }^{72,103)}$ Tritium labelled-TMX ([$\left.\left.{ }^{3} \mathrm{H}\right]-\mathrm{TMX}\right)$ binds to a high affinity site $\left(K_{\mathrm{d}} c a .10 \mathrm{nM}\right)$ in both $M$. persicae and $A$. craccivora. Binding of $\left[{ }^{3} \mathrm{H}\right]$-TMX requires the preparation of fresh membranes, as freezing destroys the binding site. Additionally, binding capacity is temperature dependent, and highly reversible, with maximum binding observed at $2^{\circ} \mathrm{C}$ and almost a $50 \%$ loss at $30^{\circ} \mathrm{C} .{ }^{103,104)}$ Although in more recent studies this temperature dependency was far less apparent. ${ }^{105)}$ The biochemical mechanism and physiological meaning behind this temperaturedependency versus the aphid membrane procedures is presently unknown.

Nicotine displacement of both $\left[{ }^{3} \mathrm{H}\right]-$ TMX or $\left[{ }^{3} \mathrm{H}\right]$-IMI has comparable $\mathrm{IC}_{50}$ values, demonstrating that the high affinity TMX binding site lies at a nAChR. ${ }^{67,104)}$ Interestingly, the association of $\left[{ }^{3} \mathrm{H}\right]-\mathrm{TMX}$ in $M$. persicae is biphasic in manner and Scatchard analysis of saturation plots are non-linear, hinting that as with imidacloprid, more than one $\mathrm{nAChR}$ binding site may exist for TMX. ${ }^{62,104)}$ Close analogues of TMX are potent displacers of $\left[{ }^{3} \mathrm{H}\right]$-IMI e.g., $\mathrm{N}$-desmethyl TMX, ${ }^{71,104,105)}$ demonstrating that the oxadiazine residue itself does not select for different nAChR forms. Additionally, $N$-methyl IMI - a very close analogue of IMI (but with an $N$-methyl additional substituent as in TMX) is very weak at displacing $\left[{ }^{3} \mathrm{H}\right]$-IMI with a $K_{\mathrm{i}}$ almost identical to TMX. ${ }^{106,107)}$ Therefore, in terms of the nAChR and the relationship between TMX and IMI, differential pharmacology via $\mathrm{N}$-methyl substitution combined with cyclic or acyclic configurations, appears to possibly underlie the selectivity between distinct neonicotinoid binding sites. ${ }^{103,105,107)}$

As with IMI and clothianidin, TMX has similar rapid neuronal blocking effects on the exposed $P$. americana nerve cord, an effect which is inconsistent with the procide hypothesis, $\left.{ }^{106}\right)$ although this effect is not always replicated between studies. ${ }^{97)}$ However, an analogue of dinotefuran (an $\mathrm{N}$-methyl neonicotinoid, see below) containing the oxadiazine sub-structure is also potently neuroactive on the isolated cockroach nerve cord. ${ }^{108)}$ Taken together with the above $\left[{ }^{3} \mathrm{H}\right]$-IMI displacement studies, this clearly demonstrates that the oxadiazine residue does not impede direct interaction with or modulation of native insect nAChRs. The differences between studies using oxadiazinecontaining neonicotinoids on isolated/exposed $P$. americana nerves is most likely to be due to preparational differences and physico-chemical factors for achieving effective compound exposure at the required cercal afferent/giant interneuron synapse. $^{109)}$

A very clear demonstration that TMX is an outright nAChR agonist came in two separate studies from Neil Millar's laboratory. TMX stimulated a cationic current in Xenopus oocytes expressing either $\mathrm{Nl} \alpha 1$ with $\operatorname{rat} \beta 2$ or $\mathrm{Nl} \alpha 3 / \mathrm{Nl} \alpha 8$ with $\operatorname{rat} \beta 2$, with similar potency to the other commercial neonicotinoids. ${ }^{54,110)}$ This could not be the result of metabolism, as TMX is stable in solution and receptor responsiveness was equivalent to that of the other commercial neonicotinoids. ${ }^{106)}$ The fact that $\mathrm{Nl} \alpha 1$, $\mathrm{Nl} \alpha 2$ and $\mathrm{Nl} \alpha 8$ in combination with a $\operatorname{rat} \beta 2$ subunit did not apparently discriminate the commercial neonicotinoids argues that in native insects the $\beta$-subunit has an important role in discerning target site selectivity. ${ }^{111)}$

In summary there is now convincing evidence from whole insect binding studies and electrophysiological experiments that TMX interacts directly with the nAChR, and modulates the receptor in a manner comparable to that of the other commercial insecticides. However, the high affinity binding sites of TMX and IMI are different in nature and this is expected to be derived from differential subunit interface combinations.

\subsection{Furanicotinyl compounds}

\subsubsection{Dinotefuran}

Like TMX, dinotefuran (DNF) is relatively weak at displacing [ $\left.{ }^{3} \mathrm{H}\right]$-IMI, with a typical $\mathrm{IC}_{50}$ of $c a$. $100 \mathrm{nM}$ (although this value varies between insect species), implying potential differences between IMI and DNF binding sites. ${ }^{96,112)}$ Tritiated-dinotefuran $\left(\left[{ }^{3} \mathrm{H}\right]-\mathrm{DNF}\right)$ has a high affinity binding site in cockroach with a $K_{\mathrm{d}}$ value of $13 \mathrm{nM}$, although the $B_{\max }$ is relatively low when compared to $\left[{ }^{3} \mathrm{H}\right] \alpha$-BGTX and $\left[{ }^{3} \mathrm{H}\right]$-epibatidine binding studies, implying that DNF binds to a specific subpopulation of nAChRs. ${ }^{113)}$ It will be of interest to study in detail the kinetics and saturation isotherms for $\left[{ }^{3} \mathrm{H}\right]$-DNF in homopteran insects to understand whether like IMI, more than one binding site exists.

The displacement characteristics of $\left[{ }^{3} \mathrm{H}\right]$-DNF have been investigated in Homalodisca coagulate (glassy winged sharpshooter), a hemipteran pest. Interestingly, $\mathrm{ACh}$ is at least 2 orders of magnitude more potent at displacing $\left[{ }^{3} \mathrm{H}\right]-\mathrm{DNF}$ than displacing either $\left[{ }^{3} \mathrm{H}\right]$-IMI or $\left[{ }^{3} \mathrm{H}\right]$-acetamiprid. ${ }^{37,96,114)}$ The displacement profiles of commercial neonicotinoids against $\left[{ }^{3} \mathrm{H}\right]-\mathrm{DNF}$ in $H$. coagulate is quite different to that observed in D. melanogaster. This implies that DNF does indeed have a specific pharmacology in hemipteran insects and the nature of its binding site is distinct to that of IMI. ${ }^{96)}$

Probably the most powerful evidence that DNF interacts with nAChRs in a unique manner to the other commercial neonicotinoids, has come from studies on the Y151S target site resistant $N$. Lugens $\alpha$-subunits when expressed in Xenopus oocytes. Subunits composed of $\mathrm{Nl} \alpha 1$ with the Y151S mutation in combination with rat $\beta 2$ demonstrated that the $I_{\max }$ exerted by DNF was 
$81 \%$ that of the wildtype control. In contrast, the mutation severely affected all other neonicotinoids, displaying $I_{\max }$ currents between $13-22 \%$ of the wildtype control. This clearly implies a different mode of binding and/or channel modulation for DNF in comparison to the other neonicotinoids. ${ }^{21,67)}$ As demonstrated in Xenopus oocytes with wildtype Nl $\alpha 1$, DNF clearly has the potential to interact at the same nAChRs as the other neonicotinoids, although (as observed with TMX) the influence of native insect $\beta$ receptors is unknown. This data strongly suggests that the specific amino acids of the nAChR that are involved in DNF recognition and/or channel modulation have differences to that of the other neonicotinoids.

\subsection{Sulfoximines}

\subsubsection{Sulfoxaflor}

Sulfoxaflor (SFX), discovered by Dow Agrosciences, is a novel insecticide for the control of sucking pest insects first commercialized in 2012. ${ }^{53,115)}$ As with the conventional neonicotinoids, the inspiration behind SFX was again not nicotine but the unique sulfoximine moiety. ${ }^{116)}$ An attractive feature of SFX is its activity on whitefly that display metabolic-based resistance to the earlier commercialized neonicotinoids, possibly by virtue of the fact that SFX does not contain an amine nitrogen present in all previously commercialized neonicotinoids. Aliphatic carbons attached to amine nitrogen groups are susceptible to monoxygenases degradation and it is suggested that this structural difference underlies SFX's enhanced metabolic robustness. ${ }^{117)}$ Additionally, SFX contains a methyl group at the bridge between the heterocycle and sulphoximine, the equivalent of which, in all neonicotinoids to date, markedly reduces potency. ${ }^{102,108)}$ Such structural differences have been proposed to differentiate SFX from the other neonicotinoids in the manner with which it interacts at the nAChRs. ${ }^{91,118)}$ Indeed, SFX is relatively weak at displacing $\left[{ }^{3} \mathrm{H}\right]$-IMI but has a greater $I_{\max }$ on heterologously expressed $D$. melanogaster $\alpha 2 /$ chicken $\beta 2$ receptors as compared to IMI. Additionally, there is a poor relationship for sulfoximine variants between their potency to displace $\left[{ }^{3} \mathrm{H}\right]-\mathrm{IMI}$ and aphicidal activity, suggestive of a differential interaction with nAChRs. ${ }^{118)}$ Adopting an unbiased approach, using a tritiated methyl analogue of SFX $\left(\left[{ }^{3} \mathrm{H}\right]\right.$-methyl-SFX) Cutler et al. have shown a clear interaction between IMI and SFX binding sites. ${ }^{119)}$ In contrast to the dual affinity nature of $\left[{ }^{3} \mathrm{H}\right]$-IMI binding to $M$. persicae membranes, $\left[{ }^{3} \mathrm{H}\right]$-methyl-SFX binds to a single saturable site with a $K_{\mathrm{d}}$ of $2.7 \mathrm{nM}$ and a $B_{\max }$ of $78 \mathrm{fmol} / \mathrm{mg}$. A clear correlation between insecticidal toxicity and $K_{\mathrm{i}}$ displacement potency for a range of sulfoxalfor analogues demonstrated the biological relevance of this binding site. Pharmacological characterization identified the binding site as the nAChR. Interestingly, $\left[{ }^{3} \mathrm{H}\right]$-methyl-SFX was displaced by IMI with exquisite potency $\left(K_{\mathrm{i}} 35 \mathrm{pM}\right)$. Therefore, it was suggested that SFX interacts at the high affinity (sub-nM $K_{\mathrm{d}}$ ) IMI binding site but the affinity of SFX at this site in aphids is considerably higher. This observation aligns with electrophysiological studies from isolated stick insect (Carausius morosus) thoracic nerves, where both
IMI and SFX target desensitizing nAChRs. In this study too, IMI (pM) was considerably more potent at desensitising the identical ACh-induced currents, as compared to SFX (nM). Therefore, two independent studies have now identified an intimate relationship between IMI and SFX binding sites with related potency observations. Thus SFX and $\left[{ }^{3} \mathrm{H}\right]$-methyl-SFX are useful new experimental tools to probe the pharmacology of the high affinity sub-nM IMI binding site, which to date has been very tricky to tease out. The fact that SFX only interacts at the high affinity IMI binding site and has much reduced ability to interact at the second lower affinity IMI binding site, explains the relative weakness of SFX to displace $\left[{ }^{3} \mathrm{H}\right]$-IMI under standard assay conditions. ${ }^{118,119)}$ Indeed in the FRC $M$. persicae clone, in which the high affinity $\left[{ }^{3} \mathrm{H}\right]$-IMI binding site is absent, there is no detectable high affinity binding of $\left[{ }^{3} \mathrm{H}\right]$-methyl-SFX and as observed with all the commercial neonicotinoids, this aphid strain has a high level of resistance to SFX. ${ }^{4,119)}$ At very high concentrations SFX must interact with the lower affinity IMI binding site given that it can fully displace $\left[{ }^{3} \mathrm{H}\right]-\mathrm{IMI}$ and (as do all the other neonicotinoids) will control FRC $M$. persicae. However, the tricky nature of working with $\left[{ }^{3} \mathrm{H}\right]$-methyl-SFX at such high concentrations has precluded accurate affinity measurements at such a secondary lower affinity site. It is of interest to note that SFX's spectrum is narrow compared to IMI, effectively controlling only sucking pest insects and not for example beetles such as Diabrotica balteata. As earlier noted, Lind et al. have claimed that the high affinity IMI binding site is only present in sucking pest insects, as Cutler et al. have shown this is also the binding site for SFX, this coincidence may explain the spectrum of SFX. Therefore, although the initial rationale behind the discovery of SFX was synthetic chemistry driven, there is clear evidence to suggest that convergent chemical optimization has resulted in SFX and IMI sharing a highly related binding site.

\subsection{Butenolides}

\subsubsection{Flupyradifurone}

Flupyradifurone represents a novel chemical class of $\mathrm{nAChR}$ agonists, the butenolide insecticides, with first market introduction by Bayer CropScience in Central America in April 2014. ${ }^{54)}$ This novel systemic insecticide for sucking pest control was identified by stepwise chemical evolution of the enaminocarbonyl pharmacophore inspired by existing nAChR ligands ${ }^{120-122)}$ and also recognized as a recurrent motif of natural products such as stemofoline, another botanical insecticide. ${ }^{123,124)}$ Flupyradifurone modulates insect nAChRs at the orthosteric binding site potently displacing $\left[{ }^{3} \mathrm{H}\right]$-IMI bound to $M$. domestica crude membranes with low $\mathrm{nM}$ affinity $\left(\mathrm{IC}_{50}=2.38 \pm 1.93 \mathrm{nM}\right)$. Electrophysiology experiments on the Spodoptera frugiperda central nervous system suggest that it acts as a partial agonist with an efficacy of $56 \%$ compared to $1 \mathrm{mM}$ ACh in the same preparation. ${ }^{54)}$ As with SFX, the main added value of this new nAChR competitive agonist lies in its lack of cross-resistance to whiteflies with acquired P450 metabolic resistance to IMI. Flupyradifurone is not affected by CYP6CM1 oxidative detoxi- 


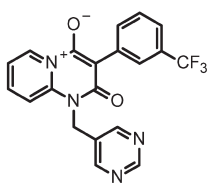

triflumezopyrim

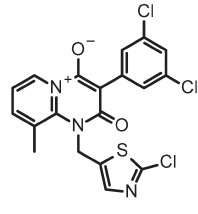

dicloromezotiaz
Fig. 6. Mesoionics.

fication when recombinantly expressed in insect cell lines and this was supported by molecular docking studies in the binding site model of this P450 enzyme in the whitefly Bemisia tabaci. However, as with all the neonicotinoids and SFX, FRC M. persicae with the R81T target-site mutation in the $\beta 1 \mathrm{nAChR}$ subunit display significant resistance to flupyradifurone. ${ }^{4)}$

\subsection{Mesoionics}

\subsubsection{Triflumezopyrim and dicloromezotiaz}

Triflumezopyrim (TFMP) (Fig. 6) is the first example of a new class of mesoionic insecticides, optimized for the control of rice hoppers including species with non-target site based resistance to existing neonicotinoids. ${ }^{55)}$ It has been developed at DuPont with first registration in 2016. This novel chemotype was discovered from a weakly insecticidal by-product originating from a fungicide optimization project. Pharmacological studies demonstrated that TFMP interacts competitively at the ACh orthosteric site of insect nAChRs, potently displacing $\left[{ }^{3} \mathrm{H}\right]-\mathrm{IMI}$ with $\mathrm{IC}_{50}=43 \mathrm{nM}$ in $M$. persicae membranes. ${ }^{125)}$ However functional activity at the $\mathrm{nAChR}$ is reported to differ from existing orthosteric modulating insecticides. Voltage clamp studies on cockroach thoracic neuron showed very weak agonism reaching less than $5 \%$ of ACh maximum response at the highest soluble concentration of $200 \mu \mathrm{M}$. This is in sharp contrast to IMI and DNF which activate nAChRs below $100 \mathrm{nM}$ in this preparation. Rather, TFMP was observed to be a potent inhibitor with an $\mathrm{IC}_{50}$ value of $0.6 \mathrm{nM}$ when co-applied with $\mathrm{ACh}$. Additionally electrophysiology experiments with chimeric Dm $\alpha 2 / \operatorname{chick} \beta 2$ nAChRs in Xenopus oocytes showed no production of an inward current by TFMP at $200 \mu \mathrm{M}$ compared to IMI which behaved as a partial agonist in these experiments with $\mathrm{EC}_{50}$ value of $1 \mu \mathrm{M}$. Such results imply that in the physiological environment of the whole insect, TFMP is likely a receptor antagonist, despite earlier findings stating the lack of insecticidal efficacy of nAChR competitive antagonists. ${ }^{126)}$ Lethargic poisoning observed after injection in the American cockroach and the lack of neuro-excitatory symptoms further support this hypothesis. Although the intended spectrum does not include aphids, as with all the conventional neonicotinoids, SFX and flupyradifurone, FRC $M$. persicae with the R81T target-site mutation in the $\beta 1$ nAChR subunit display significant resistance to TFMP (internal Syngenta data). A second chemically-related compound from the mesoionic class termed dicloromezotiaz is also believed to be in development at DuPont. In comparison to TFMP, this compound has a much lower water solubility and higher $\log P$

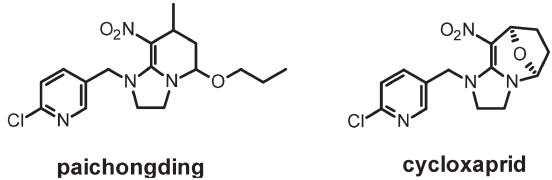

Fig. 7. cis-Neonicotinoids commercialized in China.

and has been optimized for the control of lepidopteran pests rather than hemipteran. ${ }^{127)}$ On brief exposure, dicloromezotiaz does not activate a nAChR response on whole-cell voltage clamp studies conducted with dissociated thoracic neurons from $H$. virescens, although on longer exposure a slight inward current is observed. ${ }^{128)}$

2.6.2. Chinese neonicotinoids

The successful introduction of neonicotinoids to the Chinese market has triggered significantly research efforts seeking to deliver new generation neonicotinoids. This research was promoted and funded by the Chinese government and resulted in the identification of a series of novel neonicotinoids, some of them specifically targeting the Chinese market. ${ }^{129,130)}$ With the discovery of the cis-neonicotinoids by the East China University of Science and Technology an interesting novel type of neonicotionoid was found, which possesses excellent activity against a wide range of insect pests. ${ }^{131)}$ The cis-neonicotinoids are a distinct type of neonicotinoid as the nitro group is fixed in the cisconfiguration relative to the heteroaromatic moiety. So far, two cis-neonicotinoids, paichongding and cycloxaprid, have been developed and registered in China. (Fig. 7)

Detailed studies on $N$. lugens membranes have demonstrated that paichongding (IPPA152004) displaces $\left[{ }^{3} \mathrm{H}\right]$-IMI at high concentration $(0.42 \mu \mathrm{M})$ and the high affinity IMI binding site disappears when $0.01 \mu \mathrm{M}$ IPPA152002 was added. The apparent preference for interaction at the high affinity site is comparable to that of SFX and it has been suggested that cis-neonicotinoids are useful compounds to discriminate between the two IMI binding sites. ${ }^{132)}$ However these compounds are the Michael adducts of crotonaldehydes with nitromethyleneimidazole (NMI), ${ }^{133-135)}$ a compound known since the early 1990's ${ }^{66,136,137)}$ and the authors have not ruled out the possible release of NMI in the aqueous experimental conditions. Indeed, unlike IMI, saturation studies using $\left[{ }^{3} \mathrm{H}\right]-\mathrm{NMI}$ detected only the presence of a single binding site. In terms of functional activity, whereas SFX is a high efficacy agonist, paichongding appears to have only minimal efficacy at nAChRs. In voltage-clamp electrophysiological studies on $\mathrm{Nl} \alpha 1 / \mathrm{rat} \beta 2$ hybrid $\mathrm{nAChRs}$ expressed in Xenopus oocytes, paichongding had a max inward current only $21.9 \%$ that of the current evoked by the partial agonist IMI. Such weak efficacy may imply in the physiological environment of the hemipteran insect nervous system that paichongding exerts its effects at the high affinity IMI binding site through partial release of NMI, although further detailed studies are required. ${ }^{131}$ ) Cycloxaprid $^{138)}$ is also a proinsecticide, acting as photostabilized slow-release reservoir for NMI. As appears to be a general observation with nitromethylenes such as nitenpyram, NMI is 
highly potent in $\left[{ }^{3} \mathrm{H}\right]-\mathrm{IMI}$ displacement assays, more so than IMI. ${ }^{66)}$ Given the fact that NMI clearly interacts at the same site as IMI, it's not surprising that FRC $M$. persicae display crossresistance to cycloxaprid (Syngenta internal data).

\subsection{Summary on orthosteric modulators: Defining the neonicoti- noid mode of action}

The chemical scope of nAChR orthosteric-modulating insecticides is reflected in the complex and distinct invertebrate nAChR pharmacology, with differences appearing to occur between Hemiptera, which are the principal pest target, and other insect species, such as Diptera. This may be expected given that unique $\mathrm{nAChR}$ subunits have been identified in the pea aphid genome, together with the fact that differences in the pharma- cology occurs even for highly species conserved nAChR subunits. ${ }^{76,77)}$ Therefore, care should be exercised when comparing neonicotinoid profiles across insect orders. Although the nAChR subunit pentamer combination that forms a neonicotinoid insecticidal-relevant binding site in Hemiptera (or any invertebrate) has not yet been resolved, the fact that FRC M. persicae displays significant levels of resistance to all commercialized neonicotinoids implies that the $\mathrm{Mp} \beta 1$ subunit is an essential component. The $\mathrm{nAChR}$ continues to be an attractive target for innovation in crop protection with new market introductions such as flupyradifurone providing desirable features, for example low acute honey bee toxicity. Owing to the increasing chemical diversity of compounds delivering their insecticidal effect through interaction at the orthosteric site of the nAChR, we be-

A

\begin{tabular}{|l|l|l|}
\hline \multicolumn{3}{|c|}{$\begin{array}{c}\text { Genes for nicotinic subunits in homopteran } \\
\text { insects (A. pisum) compared to Drosophila }\end{array}$} \\
\begin{tabular}{|l|l|l|}
\hline nAChR genes & A. pisum $\alpha$ & A. pisum $\beta$ \\
\hline Drosophila $\alpha$ like & $\alpha 1-4^{\#}, \alpha 6, \alpha 7$ & - \\
\hline Drosophila $\beta$ like & $\alpha 8$ & $\beta 2$ \\
\hline Distinct from Drosophila & $\alpha 9, \alpha 10$ & $\beta 1$ \\
\hline
\end{tabular}
\end{tabular}

B
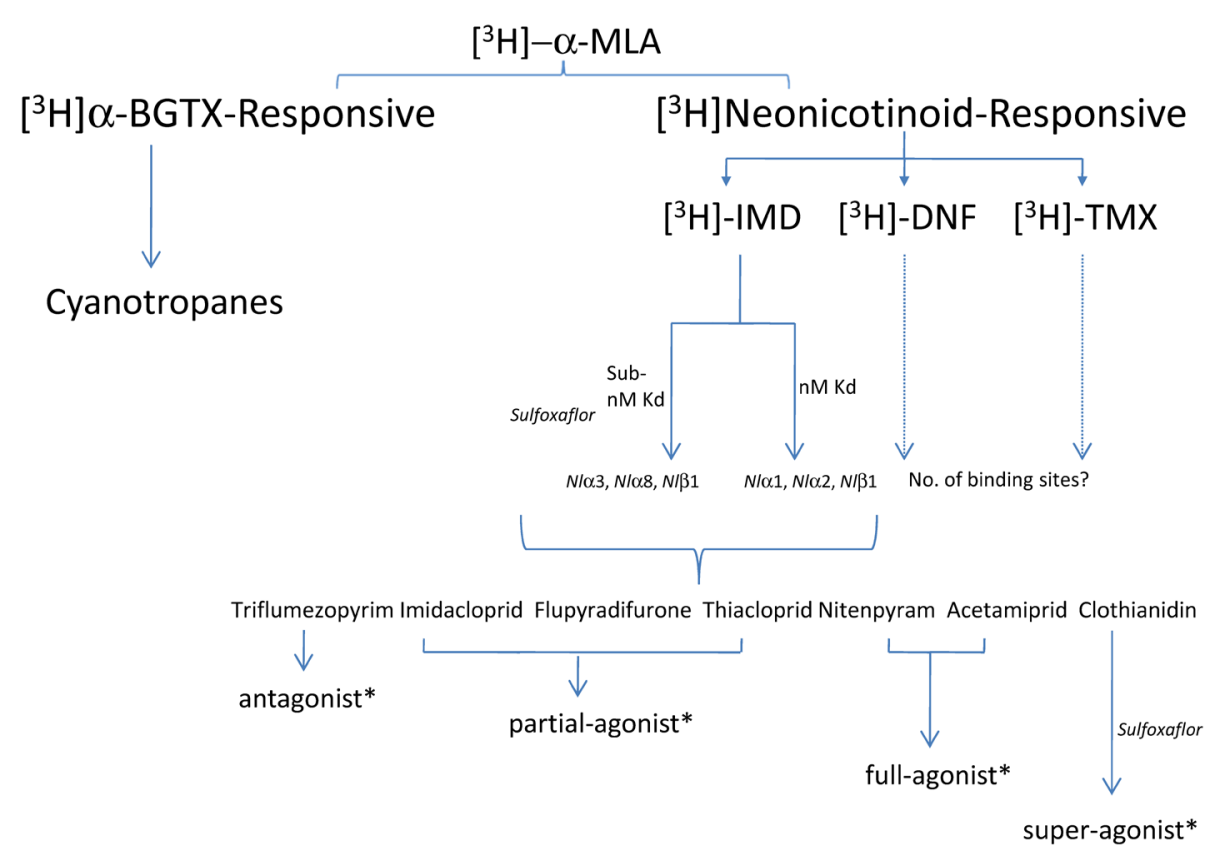

Fig. 8. Complexities of the nicotinic acetylcholine receptor and neonicotinoid pharmacology in Hemipteran insects. (A) There are $11 \mathrm{nAChR}$ genes in the Acyrthosiphon pisum genome, 3 of which are unique without close homologs in Drosophila melanogaster (\# no Dros $\alpha 5$ equivalent). The diversity of expected differential nAChRs is reflected in the complex pharmacology of nicotinoids. (B) MLA effectively labels all hemipteran nAChR subtypes with equal affinity whilst $\alpha$-BGTX/cyanotropanes and the neonicotinoids identify distinct binding sites. Within the neonicotinoid subclass there appears to be distinct binding sites for imidacloprid, dinotefuran and thiamethoxam. Imidacloprid labels two distinct binding sites, one of sub-nM (sulfoxaflor binding site) and the other of nM affinity. The effects of neonicotinoids on hemipteran nAChRs are not well understood. For illustrative purposes (*data from other insects/ heterologous expression studies) it is likely that nAChR modulators which share the same binding site can elicit distinct receptor effects. 
Table 2. Summary of IRAC Group $4 \mathrm{nAChR}$ competitive modulators and target-site interaction.

\begin{tabular}{|c|c|c|c|c|c|c|}
\hline Insecticide & Synthetic chemical class & $\begin{array}{c}\text { First } \\
\text { marketed }\end{array}$ & $\begin{array}{l}\text { IRAC Group } 4 \\
\text { sub-group }^{a)}\end{array}$ & $\begin{array}{c}\text { Altered efficacy on } \\
\text { R81T FRC } \\
\text { Myzus persicae }\end{array}$ & $\begin{array}{l}\text { Evidence for a } \\
\text { unique highest- } \\
\text { affinity binding site } \\
\text { different to that of } \\
\text { IMI }\end{array}$ & $\begin{array}{c}\text { Activity on } \\
\text { Y151S Nl } \alpha / \text { rat } \beta 2 \\
\text { heteromers }\end{array}$ \\
\hline Imidacloprid & Chloropyridyl & 1991 & A & Yes & - & No \\
\hline Clothianidin & Chlorothiazolyl & 2001 & A & Yes & No & No \\
\hline Thiamethoxam & Chlorothiazolyl & 1998 & A & Yes & Yes & No \\
\hline Dinotefuran & Furanicotinyl & 2002 & A & Yes & Yes & Yes \\
\hline Acetamiprid & Cyanoamidine chloropyridyl & 1995 & $\mathrm{~A}$ & Yes & No & No \\
\hline Thiacloprid & Cyanoamidine chloropyridyl & 2000 & A & Yes & No & No \\
\hline Nitenpyram & Nitroenamine chloropyridyl & 1995 & A & Yes & No & No \\
\hline Sulfoxaflor & Sulfoximine & 2013 & $\mathrm{C}$ & Yes & No & $?$ \\
\hline Flupyradifurone & Butenolide & 2014 & $\mathrm{D}$ & Yes & No & $?$ \\
\hline Triflumezopyrim & Mesoionic & 2016 & $\mathrm{E}$ & Yes & No & ? \\
\hline
\end{tabular}

${ }^{a)}$ Mode of action classification in IRAC takes into account not only the biochemical target-site interaction (which defines the Group) but also chemical class and activity on pest insects with non-target site based resistance to existing commercialised compounds within the particular MoA Group at the time of classification request.

lieve this necessitates defining what the commonly used generic term "neonicotinoid mode of action" refers to. Although broad structure activity relationships differ for the chemical classes acting at the nAChR agonist modulatory site, what is of most relevance for understanding the mode of action is the pharmacological profile of the commercialised individual compound itself. The following basic hemipteran receptor-pharmacology criteria driven by IMI, are proposed to define the "neonicotinoid mode of action":

1) Highest affinity (and insecticidal relevant) binding site (low $\mathrm{nM} K_{\mathrm{d}}$ ) is characterized to be the $\mathrm{nAChR}$ orthosteric site.

2) Weak displacement (low $\mu \mathrm{M}$ to $\mathrm{mM} \mathrm{IC}_{50}$ ) of radiolabelled $\alpha$-BGTX (i.e., distinct binding site/nAChR population to $\alpha$-BGTX, see Fig. 6)

3) Loss of high affinity binding site (and lower insecticidal activity) in FRC $M$. persicae due to R81T mutation.

In addition a useful further parameter is:

4) Potent displacement under standard assay conditions (low nM IC ${ }_{50}$ ) of $\left[{ }^{3} \mathrm{H}\right]$-IMI, (note DNF, SFX and TMX are outliers here)

Compounds with such a "neonicotinoid mode of action" act at a highly-related target site yet span the full efficacy range at nAChRs from antagonism through to super agonism (Fig. 8). The parameters outlined above are relatively broad, but encapsulate all commercial synthetic nAChR agonist modulating insecticides discussed in this review as classified by IRAC within Group 4 (Table 2). Such chemistry (including new market entries SFX, flupyradifurone and TFMP) is within the same IRAC Group since they all share a common target-site. As for any IRAC numbered mode of action group, insecticides with a neonicotinoid mode of action should not be rotated in the field (unless there is no other viable control method) in order to minimize selection pressure and the further spread of target-site resistance (see table). ${ }^{139)}$ All major agrochemical companies are members of IRAC and committed to recommending rotation practices for delaying resistance development. The insecticide mode of action forms the basis for developing appropriate insect resistance management (IRM) recommendations. Hence, understanding the pharmacological relationship to existing insecticides for new nAChR-modulating insecticides is absolutely necessary to ensure implementation of sound IRM strategies and maintain effectiveness of the available insecticidal tool kit.

\section{3. nAChR allosteric modulators}

\subsection{Spinosyns}

The spinosyns are a group of macrocylic lactones derived from the soil actinomycete Saccharopolyspora spinosa. The natural product spinosad and the semi-synthetic derivative spinoteram are marketed by Dow Agrosciences for the control of lepidopteran and dipteran pests. The spinosyns act to modulate the nAChR channel but at a site distinct to that of the ACh binding domain, ${ }^{140,141)}$ clearly implying differences to the neonicotinoids, hence their classification within a distinct IRAC Grouping. The mechanism by which spinosyns interact with the nAChR was not straightforward to elucidate. In radioligand displacement studies, spinosyns do not interfere with $\left[{ }^{3} \mathrm{H}\right]-\alpha$-BGTX, $\left[{ }^{3} \mathrm{H}\right]$ IMI, $\left[{ }^{3} \mathrm{H}\right]$-MLA or $\left[{ }^{3} \mathrm{H}\right]$-epibatidine binding to invertebrate nAChRs. ${ }^{142)}$ Attempts to develop a robust binding assay with a spinosyn radiolabel have proved challenging since $\left[{ }^{3} \mathrm{H}\right]$-spinosyn itself does not bind with high level specificity to native insect membranes. However, inclusion of $\mathrm{nAChR}$ agonists such as nicotine allows a high affinity binding site for $\left[{ }^{3} \mathrm{H}\right]$-spinosyn to be unmasked. ${ }^{143)}$ This key finding clearly demonstrates, that the principle site of interaction for spinosyns is the nAChR. Other channel modulators were without affect, ruling out the GABA $r d l$ receptor as a principle target. ${ }^{105,144)}$ Demonstrating that spinosyns act on a population of nAChRs that are not targeted by neonicotinoids, IMI only weakly stimulates the binding of 


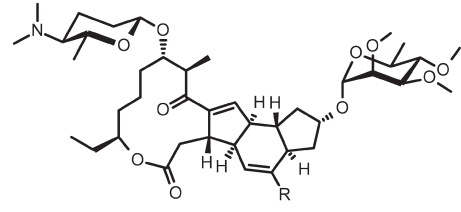

Spinosad (natural product) main components spinosyn $A(R=H)$ and spinosyn $\mathrm{D}(\mathrm{R}=\mathrm{Me})$

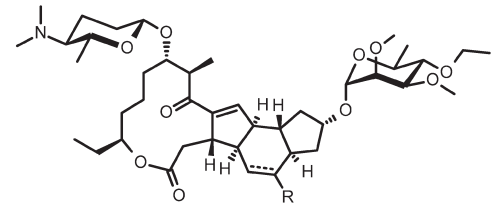

Spinetoram (semisynthetic product) main components spinosyn $\mathrm{J}(\mathrm{R}=\mathrm{H}, \mathrm{C} 5-\mathrm{C} 6$ single bond) and spinosyn $L(R=M e, C 5-C 6$ double bond $)$

Fig. 9. Structure of spinosyns and spinetoram.

$\left[{ }^{3} \mathrm{H}\right]$-spinosyn. These observations are in line with electrophysiological recordings on isolated $P$. americana nerves, where in the presence of $\mathrm{ACh}, \mathrm{nM}$ concentrations of spinosyn stimulate the $\alpha$-BGTX-sensitive nAChD current, but are without effect at the IMI sensitive $\mathrm{nAChN} .{ }^{65)}$ Thus, spinosyns are not direct agonists, rather they act at an allosteric site to synergistically enhance agonist-mediated nAChR channel activation.

A direct link between the $\mathrm{AChR}$ and the insecticidal activity of spinosyn has been provided by $\mathrm{nAChR}$ receptor mutations that provide high level insect resistance. The generation of spinsosyn resistance in D. melanogaster has been achieved via two distinct approaches. Watson and colleagues opted for an unbiased forward genetics approach using random chemical mutagenesis (EMS), whilst Perry et al. undertook a deficiency based approach, screening hemizygous $D$. melanogaster lacking known nAChR subunit genes. ${ }^{145,146)}$ Both methods identified that an alteration (mutation or chromosome deficiency) in Dm $\alpha 6$ resulted in D. melanogaster strains that had high level resistance to spinosad (Fig. 9). Validating the significance of the Dm $\alpha 6$ subunit for insecticidal toxicity, introduction of an EMS-isolated mutation into a controlled genetic background via the CRISPR/ Cas9 system was itself sufficient to generate resistance to spinosad in D. melanogaster. ${ }^{147}$ ) These findings from the model organism Drosophila, are in line with investigations of spinosyn resistance in agricultural pests. High-level resistance in the diamond back moth Plutella xylostella was widespread in Hawaii within 2 years of first use ${ }^{148)}$ and is associated with a mutation within an intron region of $\mathrm{Px} \alpha 6$, leading to gene mis-splicing and a predicted truncated Px $\alpha 6$ nAChR subunit. ${ }^{149)}$ Spinosynresistance in western flower thrips Frankliniella occidentalis has been identified to a point mutation G275E located at the third $\alpha$-helical TMD of Fo $\alpha 6{ }^{150)}$ Laboratory selection of the oriental fruit fly Bactrocera dorsalis generated high-level spinosyn resistance also associated with non-functional $\alpha 6$ subunits due to truncated transcripts. ${ }^{151)}$ Given these observations it has been suggested that any mutation that causes a loss of $\alpha 6$ will confer resistance to spinosad. ${ }^{147)}$ In all cases so far though, spinosyn resistance has been incompletely dominant. However such alterations in $\alpha 6$ invertebrate nAChRs are without any serious or even no observable fitness penalty associated. ${ }^{139,147)}$ This may be a result of receptor redundancy, as the $\operatorname{Dm} \alpha 6$ subunit shares a high degree of homology to the $\operatorname{Dm} \alpha 5$ and $\operatorname{Dm} \alpha 7$ subunits, which are known to be required for the formation of $\alpha$-BGTX-sensitive but IMI insensitive nAChRs. ${ }^{152)}$ Biochemical, electrophysiological and resistance based-approaches tie in to collectively imply that the spinosyns act as allosteric modulators, at a binding site located within the TMD of $\alpha$-BGTX-sensitive $\alpha 6$ containing invertebrate nAChRs. ${ }^{147)}$ The vertebrate $\alpha 7$ is the closest vertebrate orthologue of $\mathrm{Dm} \alpha 6$ and there are now many synthetic small molecule allosteric modulators identified. Thus it is reasonable to expect identification of fully synthetic low molecular weight allosteric modulators of invertebrate nAChRs is feasible. Cheaper synthetic allosteric modulators may open up low-cost volume markets currently not commercially viable for the spinosyns. Introduction of such compounds must be accompanied with strict IRM programs to minimize the onset of resistance given the apparent low-fitness penalty of altered $\alpha 6$ function, in order to maintain the durability and efficacy of any such products. ${ }^{139)}$

\section{4. $\mathrm{nAChR}$ channel blockers}

\subsection{Nereistoxin analogues (Fig. 10)}

Nereistoxin (NTX) is derived from the marine annelid worm Lumbriconereis heteropoda and is potently toxic to insects via blockade of nicotinic synapses. ${ }^{153)}$ A number of synthetic derivatives have been approved for use (cartap, bensultap, thiocyclam and thiosultap) although the spectrum of such compounds is broad, crop selectivity issues means these compounds only occupy a niche market and have low commercial success. NTX acts as an antagonist of the nAChR at both vertebrate and Drosophila/vertebrate hybrids when expressed in Xenopus oocytes. In these studies there was little evidence for differential selectivity between insect and mammal forms, but as with neonicotinoid

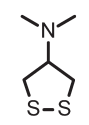

nereistoxin

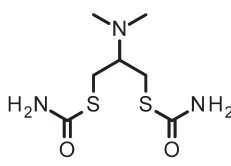

cartap

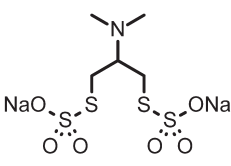

thiosultap sodium

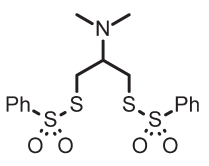

bensultap

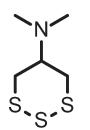

thiocyclam

Fig. 10. Structure of nereistoxin and its analogues. 
studies, the influence of native insect $\beta$ receptors is not directly known. ${ }^{154)}$ Blockade of the nAChR by NTX is non-competitive in nature and at a site distinct to that of the agonist binding site or the $\alpha$-BGTX binding site. Cartap is generally regarded as a procide of NTX. However, studies on rat PC12 cells have suggested that cartap can act directly at the nAChR as an open channel blocker. ${ }^{155)}$ Although a binding assay with a tritiated version of NTX has proven challenging to develop, studies have investigated the relationship of NTX and cartap at the IMI binding site and at the phenycyclidine (PCP) channel blocking site within the nAChR. Both cartap and NTX displace tritiated-thienylcyclohexylpiperidine $\left(\left[{ }^{3} \mathrm{H}\right]-\mathrm{TCP}\right)$ (a close analogue of PCP) with similar affinity and the interaction between TCP and cartap is competitive in nature, however cartap has little ability to displace $\left[{ }^{3} \mathrm{H}\right]$-IMI, identifying differences between NTX analogues and neonicotinoids. These in vitro studies supported the hypothesis that cartap is active in its own right and that since the reaction was reversible, also ruled out the reduction of disulphide bonds that lie near the agonist binding site, as a mechanism of channel antagonism. ${ }^{156)}$ However, a follow up study noted that cartap was very unstable in water/pH 7.4 and the actual compound responsible for the actions assigned to cartap in vitro is likely instead to be due to the dithiol derivative. ${ }^{157)}$ The situation in whole insects is expected to be more complicated since cartap is converted to NTX in plants, so the lethal effects are likely to be delivered by NTX rather than cartap or immediate derivatives. ${ }^{158)}$

\section{Future research directions}

The future research for insecticides acting at the invertebrate nAChR can be split into two related directions: receptor pharmacology and metabolising systems. A focus for industrial agrochemical research will be on hemipteran pests as there are no trait solutions and the current commercial insecticide tool kit for their control is dwindling. From the nAChR perspective, hemipteran insects clearly display stark pharmacological differences to other insects and the sequencing of further hemipteran genomes, will start to piece together the uniqueness of this insect order. A clear breakthrough would be the ability to express native insect $\beta \mathrm{nAChR}$ subunits in vitro. This has been a long standing goal and there are thoughts as to the challenges that lie ahead on this front. ${ }^{21)}$ In addition, the further identification of subunits that contribute actual nAChRs in vivo will aid expression studies to truly understand the pharmacology of native insect nAChRs. The recent findings of aphids with target siteresistance to neonicotinoids poses new challenges for nAChRmodulating chemistry. Whether alterations in gene expression/ nAChR point mutation have a restrictive fitness penalty is not yet clear.

Improving knowledge on insect xenobiotic metabolism, particularly in Hemiptera and pollinating insects, will provide new information for the rational design of next generation insecticides. As demonstrated by the recent market introduction of SFX and flupyradifurone, there is still potential for novel chem- istry classes within the neonicotinoid mode of action displaying desirable features over earlier commercialised chemistry. A key challenge for any future insecticide chemistry is that it must combat resistance in key insect pests whilst satisfying the increasingly challenging regulatory environment in multiple global regions. It is clear that our overall knowledge on Hemiptera needs to be improved if effective new chemistry for sucking pest control is to be discovered.

\section{References}

1) P. McDougall: Agri Service 2016-product section. Weblink: https:// www.phillipsmcdougall.com (Accessed on 23 June, 2017)

2) P. Jeschke, R. Nauen, M. Schindler and A. Elbert: J. Agric. Food Chem. 59, 2897-2908 (2011).

3) C. Bass, A. M. Puinean, M. Andrews, P. Cutler, M. Daniels, J. Elias, V. L. Paul, A. J. Crossthwaite, I. Denholm, L. M. Field, S. P. Foster, R. Lind, M. S. Williamson and R. Slater: BMC Neurosci. 12, 51 (2011).

4) C. Bass, I. Denholm, M. S. Williamson and R. Nauen: Pestic. Biochem. Physiol. 121, 78-87 (2015).

5) R. Nauen, N. Stumpf and A. Elbert: Pest Manag. Sci. 58, 868-875 (2002).

6) A. M. Puinean, I. Denholm, N. S. Millar, R. Nauen and M. S. Williamson: Pestic. Biochem. Physiol. 97, 129-132 (2010).

7) A. M. Puinean, S. P. Foster, L. Oliphant, I. Denholm, L. M. Field, N. S. Millar, M. S. Williamson and C. Bass: PLoS Genet. 6, e1000999 (2010).

8) J. Z. Zhao, B. A. Bishop and E. J. Grafius: J. Econ. Entomol. 93, 1508$1514(2000)$.

9) E. R. Nauen and A. McCaffery: "Modern Crop Protection Compounds," vol. 3, ed. by W. Kramer, U. Schirmer, Wiley-VCH, Weinheim, pp. 753-772, 2007.

10) www.irac-online.org (Accessed on 23 June, 2017).

11) R. Nauen, M. Ghanim and I. Ishaaya: Pest Manag. Sci. 70, 14381439 (2014).

12) X. Shao, Z. Ye, H. Bao, Z. Liu, X. Xu, Z. Li and X. Qian: Chimia (Aarau) 65, 957-960 (2011).

13) J. Changeux and S. J. Edelstein: Curr. Opin. Neurobiol. 11, 369-377 (2001).

14) N. Unwin: Novartis Found. Symp. 245, 5-15, discussion, 15-21, 165-168 (2002).

15) S. H. Thany, G. Lenaers, V. Raymond-Delpech, D. B. Sattelle and B. Lapied: Trends Pharmacol. Sci. 28, 14-22 (2007).

16) D. Kalamida, K. Poulas, V. Avramopoulou, E. Fostieri, G. Lagoumintzis, K. Lazaridis, A. Sideri, M. Zouridakis and S. J. Tzartos: FEBS J. 274, 3799-3845 (2007).

17) S. M. Sine and P. Taylor: J. Biol. Chem. 256, 6692-6699 (1981).

18) J. Dupuis, T. Louis, M. Gauthier and V. Raymond: Neurosci. Biobehav. Rev. 36, 1553-1564 (2012).

19) M. Tomizawa, N. S. Millar and J. E. Casida: Insect Biochem. Mol. Biol. 35, 1347-1355 (2005).

20) S. J. Lansdell, T. Collins, J. Goodchild and N. S. Millar: BMC Neurosci. 13, 73 (2012).

21) D. Bertrand, M. Ballivet, M. Gomez, S. Bertrand, B. Phannavong and E. D. Gundelfinger: Eur. J. Neurosci. 6, 869-875 (1994).

22) T. Collins, S. J. Lansdell and N. S. Millar: Biochem. Pharmacol. 78, 902 (2009).

23) M. D. Adams, S. E. Celniker, R. A. Holt, C. A. Evans, J. D. Gocayne, P. Amanatides, S. E. Scherer, P. W. Li, R. A. Hoskins, R. F. Galle, et 
al.: Science 287, 2185-2195 (2000).

24) R. A. Holt, G. M. Subramanian, A. Halpern, G. G. Sulton, R. Charlab, D. R. Nusskern, A. G. Clark, J. M. Ribeiro, R. Wides, S. L. Salzberg, et al.: Science 298, 129-149 (2002).

25) G. M. Weinstock, G. E. Robinson, R. A. Gibbs, K. C. Worley, J. D. Evans, R. Maleszka, H. M. Robertson, D. B. Weaver, M. Beye, P. Bork, et al.: Nature 443, 931-949 (2006).

26) S. Richards, R. A. Gibbs, G. M. Weinstock, S. J. Brown, R. Denell, R. W. Beeman, G. Bucher, M. Friedrich, C. J. P. Grimmelikhuijzen, M. Kingler, et al.: Nature 452, 949-955 (2008).

27) S. Richards, R. A. Gibbs, N. M. Gerardo, N. Moran, A. Nakabachi, S. Richards, D. Stern, D. Tagu, A. C. C. Wilson, D. Muzny, et al.: PLoS Biol. 8, e1000313 (2010).

28) A. K. Jones, L. A. Brown and D. B. Sattelle: Invert. Neurosci. 7, 67-73 (2007).

29) A. K. Jones and D. B. Sattelle: BMC Genomics 8, 327 (2007).

30) P. N. Kao and A. Karlin: J. Biol. Chem. 261, 8085-8088 (1986).

31) R. P. Dale, A. K. Jones, C. Tamborindeguy, T. G. Davies, J. S. Amey, S. Williamson, A. Wolstenholme, L. M. Field, M. S. Williamson, T. K. Walsh and D. B. Sattelle: Insect Mol. Biol. 19(Suppl 2), 141-153 (2010).

32) K. Sumikawa and V. M. Gehle: J. Biol. Chem. 267, 6286-6290 (1992).

33) F. D. Rinkevich and J. G. Scott: Insect Mol. Biol. 18, 233-242 (2009).

34) R. M. Johnson: Annu. Rev. Entomol. 60, 415-434 (2015).

35) O. Lundin, M. Rundlöf, H. G. Smith, I. Fries and R. Bommarco: PLoS One 10, e0136928 (2015).

36) M. Tomizawa and I. Yamamoto: J. Pestic. Sci. 18, 91-98 (1993).

37) I. Yamamoto: "Nicotinoid Insecticides and the Nicotinic Acetylcholine Receptor," ed. by I. Yamamoto and J. E. Casida, Springer, Tokyo, pp. 3-27, 1999.

38) S. Kagabu: Rev. Toxicol. 1, 75-129 (1997).

39) P. Jeschke and R. Nauen: Pest Manag. Sci. 64, 1084-1098 (2008).

40) I. Yamamoto, H. Kamimura, R. Yamamoto, S. Sakai and M. Goda: Agric. Biol. Chem. 26, 709 (1962).

41) J. W. Daly: Cell. Mol. Neurobiol. 25, 513-552 (2005).

42) S. B. Soloway, A. C. Henry, W. D. Kollmeyer, W. M. Padgett, J. E. Powell, S. A. Roman, C. H. Tieman, R. A. Corey and C. A. Horne: “Advances in Pesticide Science Part 2," ed. by H. Geissbühler, G. T. Brooks and P. C. Kearney, Pergamon, Oxford, pp. 206-217, 1979.

43) K. Matsuda, S. D. Buckingham, D. Kleier, J. J. Rauh, M. Grauso and D. B. Sattelle: Trends Pharmacol. Sci. 22, 573-580 (2001).

44) M. E. Schroeder and R. F. Flattum: Pestic. Biochem. Physiol. 22, 148 160 (1984).

45) R. Zwart, M. Oortgiesen and H. P. M. Vijverberg: Environ. Toxicol. Pharmacol. 228, 165-169 (1992).

46) S. Kagabu: J. Agric. Food Chem. 59, 2887-2896 (2011).

47) I. Minamida, K. Iwanaga, T. Tabuchi, I. Aoki, T. Fusaka, H. Ishizuka and T. Okauchi: J. Pestic. Sci. 18, 41-48 (1993).

48) H. Takahashi, J. Mitsui, N. Takakusa, M. Matsuda, H. Yoneda, J. Suzuki, K. Ishimitsu and T. Kishimoto: Brighton Crop Protection Conference - Pests and Diseases (2-9), pp. 89-96, 1992.

49) P. Jeschke, K. Moriya, R. Lantzsch, H. Seifert, W. Lindner, K. Jelich, A. Gohrt, M. E. Beck and W. Etzel: Pflanzenschutz-Nachr. Bayer. 54, 147-160 (2001)

50) P. Maienfisch, F. Brandl, W. Kobel, A. Rindlisbacher and R. Senn: "Nicotinoid Insecticides and the Nicotinic Acetylcholine Receptor", ed. by I. Yamamoto and J. E. Casida, Springer, Tokyo, pp. 177-209, 1999.

51) Y. Ohkawara, A. Akayama, K. Matsuda and W. Andersch: Brighton
Crop Protection Conference-Pests and Diseases pp. 51-58 (2002).

52) T. Wakita, N. Yasui, E. Yamada and D. Kishi: J. Pestic. Sci. 30, 122123 (2005).

53) M. R. Loso, T. C. Sparks, J. Babcock, I. Denholm, B. C. Gerwick, K. Gorman, V. B. Hegde, J. X. Huang, D. Kelley, B. M. Nugent, et al.: Discovery, biology and biochemistry of sulfoxaflor: A new sapfeeding insecticide. Abstracts of Papers, 239th ACS National Meeting, San Francisco, CA, United States, March 21-25, p. AGRO-119 (2010).

54) R. Nauen, P. Jeschke, R. Velten, M. E. Beck, U. EbbinghausKintscher, W. Thielert, K. Wölfel, M. Haas, K. Kunz and G. Raupach: Pest Manag. Sci. 71, 850-862 (2015).

55) C. W. Holyoke Jr, W. Zhang, T. F. Pahutski Jr, G. P. Lahm, M.-H. Thi Tong, D. Cordova, M. E. Schroeder, E. A. Benner, J. J. Rauh, R. F. Dietrich, et al.: ACS Symp. Ser. 1204, 365-378 (2015).

56) K. Matsuda, S. Kanaoka, M. Akamatsu and D. B. Sattelle: Mol. Pharmacol. 76, 1-10 (2009).

57) P. Jeschke, R. Nauen and M. E. Beck: Angew. Chem. Int. Ed. 52, 9464-9485 (2013)

58) D. Bai, S. C. R. Lummis, W. Leicht, H. Breerc and D. B. Sattelle: Pestic. Sci. 33, 197-204 (1991).

59) S. Buckingham, B. Lapied, H. Corronc and F. Sattelle: J. Exp. Biol. 200, 2685-2692 (1997).

60) M. Y. Liu and J. E. Casida: Pestic. Biochem. Physiol. 46, 40-46 (1993).

61) H. Nishiwaki, Y. Nakagawa, M. Kuwamura, K. Sato, M. Akamatsu, K. Matsuda, K. Komai and H. Miyagawa: Pest Manag. Sci. 59, 10231030 (2003)

62) R. J. Lind, M. S. Clough, S. E. Reynolds and F. G. P. Earley: Pestic. Biochem. Physiol. 62, 3-14 (1998).

63) M. Tomizawa and I. Yamamoto: J. Pestic. Sci. 17, 231-236 (1992).

64) N. Zhang, M. Tomizawa and J. E. Casida: Neurosci. Lett. 371, 56-59 (2004).

65) V. L. Salgado and R. Saar: J. Insect Physiol. 50, 867-879 (2004).

66) M. Y. Liu, B. Latli and J. E. Casida: Pestic. Biochem. Physiol. 50, 171182 (1994).

67) P. Wiesner and H. Kayser: J. Biochem. Mol. Toxicol. 14, 221-230 (2000).

68) Z. Liu, M. S. Williamson, S. J. Lansdell, I. Denholm, Z. Han and N. S. Millar: Proc. Natl. Acad. Sci. U.S.A. 102, 8420-8425 (2005).

69) X. Xu, H. Bao, X. Shao, Y. Zhang, X. Yao, Z. Liu and Z. Li: Insect Mol. Biol. 19, 1-8 (2010).

70) S. L. Chao, T. J. Dennehy and J. E. Casida: J. Econ. Entomol. 90, 879882 (1997).

71) A. Zhang, H. Kayser, P. Maienfisch and J. E. Casida: J. Neurochem. 75, 1294-1303 (2000)

72) E. Taillebois, A. Beloula, S. Quinchard, S. Jaubert-Possamai, A. Daguin, D. Servent, D. Tagu, S. H. Thany and H. Tricoire-Leignel: PLoS One 9, e96669 (2014).

73) M. Tomizawa, Z. Wen, H.-L. Chin, H. Morimoto, H. Kayser and J. E. Casida: J. Neurochem. 78, 1359-1366 (2001).

74) S. Kagabu, P. Maienfisch, A. Zhang, J. Granda-Minones, J. Haettenschwiler, H. Kayser, T. Maetzke and J. E. Casida: J. Med. Chem. 43, 5003-5009 (2000).

75) J. Li, Y. Shao, Z. Ding, H. Bao, Z. Liu, Z. Han and N. S. Millar: Insect Biochem. Mol. Biol. 40, 17-22 (2010).

76) F. Sgard, S. P. Fraser, M. J. Katkowska, M. B. Djamgoz, S. J. Dunbar and J. D. Windass: J. Neurochem. 71, 903-912 (1998).

77) Y. Huang, M. S. Williamson, A. L. Devonshire, J. D. Windass, S. J. Lansdell and N. S. Millar: J. Neurochem. 73, 380-389 (1999).

78) Z. Liu, Z. Han, Y. Zhang, F. Song, X. Yao, S. Liu, J. Gu and N. S. Mil- 
lar: J. Neurochem. 108, 498-506 (2009).

79) Z. Liu, M. S. Williamson, S. J. Lansdell, Z. Han, I. Denholm and N. S. Millar: J. Neurochem. 99, 1273-1281 (2006).

80) Z. Yixi, Z. Liu, Z. Han, F. Song, X. Yao, Y. Shao, J. Li and N. S. Millar: J. Neurochem. 110, 1855-1862 (2009).

81) A. J. Crossthwaite, S. Rendine, M. Stenta and R. Slater: J. Chem. Biol. 7, 125-128 (2014).

82) K. Hirata, R. Kiyota, A. Matsuura, S. Toda, A. Yamamoto and T. Iwasa: J. Pestic. Sci. 40, 25-31 (2015).

83) X.-G. Shi, Y.-K. Zhu, X.-M. Xia, K. Qiao, H.-Y. Wang and K.-Y. Wang: J. Food Agric. Environ. 10, 1227-1230 (2012).

84) X. Chen, F. Li, A. Chen, K. Ma, P. Liang, Y. Liu, D. Song and X. Gao: Pestic. Biochem. Physiol. 141, 1-8 (2017).

85) L. Erdmanis, A. O. O’Reilly, M. S. Williamson, L. M. Field, A. Turberg and B. A. Wallace: Biochemistry 51, 4627-4629 (2012).

86) P. Déglise, B. Grünewald and M. Gauthier: Neurosci. Lett. 321, 1316 (2002).

87) R. Nauen, U. Ebbinghaus-Kintscher and R. Schmuck: Pest Manag. Sci. 57, 577-586 (2001).

88) J. Tan, J. J. Galligan and R. M. Hollingworth: Neurotoxicology 28 , 829-842 (2007).

89) P. Deglise, B. Grünewald and M. Gauthier: Neurosci. Lett. 321, 13 16 (2002).

90) L. A. Brown, M. Ihara, S. D. Buckingham, K. Matsuda and D. B. Sattelle: J. Neurochem. 99, 608-615 (2006).

91) Y. Zhang, S. Liu, J. Gu, F. Song, X. Yao and Z. Liu: Neurosci. Lett. 446, 97-100 (2008).

92) M. Ihara, T. Okajima, A. Yamashita, T. Oda, T. Asano, M. Matsui, D. B. Sattelle and K. Matsuda: Mol. Pharmacol. 86, 736-746 (2014).

93) V. L. Salgado: Neurotoxicology 56, 188-195 (2016).

94) D. R. Boina, E. O. Onagbola, M. Salyani and L. L. Stelinski: Pest Manag. Sci. 65, 870-877 (2009).

95) M. Daniels, J. S. Bale, H. J. Newbury, R. J. Lind and J. J. Pritchard: J. Insect Physiol. 55, 758-765 (2009).

96) H. Honda, M. Tomizawa and J. E. Casida: J. Agric. Food Chem. 54, 3365-3371 (2006).

97) J. Tan, J. J. Galligan and R. M. Hollingworth: Neurotoxicology 28 , 829-842 (2007)

98) I. Yamamoto, M. Tomizawa, T. Saito, T. Miyamoto, E. C. Walcott and K. Sumikawa: Arch. Insect Biochem. Physiol. 37, 24-32 (1998).

99) M. Ihara, K. Matsuda, M. Otake, M. Kuwamura, M. Shimomura, K. Komai, M. Akamatsu, V. Raymond and D. B. Sattelle: Neuropharmacology 45, 133-144 (2003).

100) M. Ihara, K. Matsuda, M. Shimomura, D. B. Sattelle and K. Komai: Biosci. Biotechnol. Biochem. 68, 761-763 (2004).

101) R. Nauen, U. Ebbinghaus-Kintscher, V. L. Salgado and M. Kaussmann: Pestic. Biochem. Physiol. 76, 55-69 (2003).

102) P. Jeschke and R. Nauen: "Comprehensive Molecular Insect Science," Vol. 5, Elsevier Pergamon, Oxford, UK, pp. 53-105, 2005.

103) H. Kayser, H. Wellmann, C. Lee, A. Decock, M. Gomes, B. Cheek, R. Lind, M. Baur, J. Hattenschwiler and P. Maienfisch: ACS Symp. Ser. 948, 67-81 (2007).

104) H. Wellmann, M. Gomes, C. Lee and H. Kayser: Pest Manag. Sci. 60 , 959-970 (2004).

105) H. Kayser, K. Lehmann, M. Gomes, W. Schleicher, K. Dotzauer, M. Moron and P. Maienfisch: Pest Manag. Sci. 72, 2166-2175 (2016).

106) S. Kagabu, N. Murata, R. Hibino, M. Hanazawa and K. Nishimura: J. Pestic. Sci. 30, 111-115 (2005)

107) H. Kayser, C. Lee, A. Decock, M. Baur, J. Haettenschwiler and P. Maienfisch: Pest Manag. Sci. 60, 945-958 (2004).
108) K. Kiriyama and K. Nishimura: Pest Manag. Sci. 58, 669-676 (2002).

109) S. H. Thany: Neuropharmacology 60, 587-592 (2011).

110) Z. Yixi, Z. Liu, Z. Han, F. Song, X. Yao, Y. Shao, J. Li and N. S. Millar: J. Neurochem. 110, 1855-1862 (2009).

111) M. Shimomura, M. Yokota, M. Ihara, M. Akamatsu, D. B. Sattelle and K. Matsuda: Mol. Pharmacol. 70, 1255-1263 (2006).

112) K. Kiriyama, H. Nishiwaki, Y. Nakagawa and K. Nishimura: Pest Manag. Sci. 59, 1093-1100 (2003).

113) S. Miyagi, I. Komaki and Y. Ozoe: Pest Manag. Sci. 62, 293-298 (2006).

114) T. Wakita, K. Kinoshita, E. Yamada, N. Yasui, N. Kawahara, A. Naoi, M. Nakaya, K. Ebihara, H. Matsuno and K. Kodaka: Pest Manag. Sci. 59, 1016-1022 (2003)

115) J. Huang, R. Rogers, N. Orr, T. Sparks, J. Gifford, M. Loso, Y. Zhu and T. Meade (Dow Agrosciences LLC) PCT Appl. WO2007149134 (2007).

116) T. C. Sparks, G. B. Watson, M. R. Loso, C. Geng, J. M. Babcock and J. D. Thomas: Pestic. Biochem. Physiol. 107, 1-7 (2013).

117) Y. Zhu, M. R. Loso, G. B. Watson, T. C. Sparks, R. B. Rogers, J. X. Huang, B. C. Gerwick, J. M. Babcock, D. Kelley, V. B. Hegde, B. M. Nugent, J. M. Renga, I. Denholm, K. Gorman, G. J. DeBoer, J. Hasler, T. Meade and J. D. Thomas: J. Agric. Food Chem. 59, 29502957 (2011).

118) G. B. Watson, M. R. Loso, J. M. Babcock, J. M. Hasler, T. J. Letherer, C. D. Young, Y. Zhu, J. E. Casida and T. C. Sparks: Insect Biochem. Mol. Biol. 41, 432-439 (2011).

119) P. Cutler, R. Slater, A. J. Edmunds, P. Maienfisch, R. G. Hall, F. G. Earley, T. Pitterna, S. Pal, V. L. Paul, J. Goodchild, M. Blacker, L. Hagmann and A. J. Crossthwaite: Pest Manag. Sci. 69, 607-619 (2013).

120) P. Jeschke, R. Nauen, O. Gutbrod, M. E. Beck, S. Matthiesen, M. Haas and R. Velten: Pestic. Biochem. Physiol. 121, 31-38 (2015).

121) H. Ohishi, T. Iihama, K. Ishimitsu, T. Yamada, R. Hatano, N. Takakusa and J. Mitsui (Nippon Soda Co.): PCT Appl. WO 9200964A1 (1992).

122) P. Jeschke, M. E. Beck, W. Kraemer, D. Wollweber, C. Erdelen, A. Turberg, O. Hansen, H.-D. Martin and P. Sauer (Bayer AG): DE 10119423 A1 (2002)

123) I. Ujváry: "Nicotinoid Insecticides and the Nicotinic Acetylcholine Receptor," ed. by I. Yamamoto and J. E. Casida, Springer, Tokyo, pp. 29-69, 1999.

124) C.-P. Tang, T. Chen, R. Velten, P. Jeschke, U. Ebbinghaus-Kintscher, S. Geibel and Y. Ye: J. Nat. Prod. 71, 112-116 (2008).

125) D. Cordova, E. A. Benner, M. E. Schroeder, C. W. Holyoke Jr., W. Zhang, T. F. Pahutski, R. M. Leighty, D. R. Vincent and J. C. Hamm: Insect Biochem. Mol. Biol. 74, 32-41 (2016).

126) R. Nauen, U. Ebbinghaus-Kintscher, A. Elbert, P. Jeschke and K. Tietjen: "Biochemical Sites of Insecticide Action and Resistance" ed. by I. Ishaaya, Springer, Berlin, pp. 288-321, 2001.

127) W. Zhang, C. W. Holyoke Jr., J. Barry, D. Cordova, R. M. Leighty, M.-H. T. Tong, K. A. Hughes, G. P. Lahm, T. F. Pahutski, M. Xu, T. A. Briddell, S. F. McCann, Y. T. Henry and Y. Chen: Bioorg. Med. Chem. Lett. 27, 911-917 (2017).

128) C. W. Holyoke Jr., D. Cordova, W. Zhang, J. D. Barry, R. M. Leighty, R. F. Dietrich, J. J. Rauh, T. F. Pahutski Jr., G. P. Lahm, M. T. Tong, et al.: Pest Manag. Sci. 27, 911-917 (2017).

129) X. Shao, Z. Liu, X. Xu, Z. Li and X. Qian: J. Pestic. Sci. 38, 1-9 (2013).

130) L. Hai-bo, H. Zhi-hong and G. Bao-jial: Int. J. Adv. Multidiscip. Res. 3, 62-69 (2016) 
131) X. Shao, Z. Ye, H. Bao, Z. Liu, X. Xu, Z. Li and X. Qian: Chimia (Aarau) 65, 957-960 (2011).

132) X. Xu, H. Bao, X. Shao, Y. Zhang, X. Yao, Z. Liu and Z. Li: Insect Mol. Biol. 19, 1-8 (2010).

133) X. Shao, W. Zhang, Y. Peng, Z. Li, Z. Tian and X. Qian: Bioorg. Med. Chem. Lett. 18, 6513-6516 (2008).

134) S. Lu, X. Shao, Z. Li, Z. Xu, S. Zhao, Y. Wu and X. Xu: J. Agric. Food Chem. 60, 322-330 (2012).

135) Y. Lou, Y. Xu, Z. Chai, X. Shao, G. Zhao and Z. Li: Tetrahedron 71, 6651-6658 (2015).

136) K. Moriya, K. Shibuya, Y. Hattori, S.-I. Tsuboi, K. Shiokawa and S. Kagabu: Biosci. Biotechnol. Biochem. 56, 364-365 (1992).

137) P. Jeschke: Pest Manag. Sci. 72, 210-225 (2016).

138) X. Shao, T. L. Swenson and J. E. Casida: J. Agric. Food Chem. 61, 7883-7888 (2013).

139) T. C. Sparks and R. Nauen: Pestic. Biochem. Physiol. 121, 122-128 (2015).

140) V. L. Salgado, G. B. Watson and J. J. Sheets: Beltwide Cotton Conf. 2, 1082-1084 (1997).

141) R. Nauen, U. Ebbinghaus and K. Tietjen: Pestic. Sci. 55, 608-610 (1999).

142) N. Orr, A. J. Shaffner, K. Richey and G. D. Crouse: Pestic. Biochem. Physiol. 95, 1-5 (2009).

143) J. Blythe, P. Cutler, C. Godfrey, R. Parsons, M. Respondek, A. Russell and F. Earley: Nicotinic Acetylcholine Receptors Conference, Wellcome Trust Conference Centre, Cambridge, 23-26th April, 2008.

144) T. C. Sparks, G. D. Crouse and G. Durst: Pest Manag. Sci. 57, 896 905 (2001)

145) G. B. Watson, S. W. Chouinard, K. R. Cook, C. Geng, J. M. Gifford, G. D. Gustafson, J. M. Hasler, I. M. Larrinua, T. J. Letherer, J. C.
Mitchell, W. L. Pak, V. L. Salgado, T. C. Sparks and G. E. Stilwell: Insect Biochem. Mol. Biol. 40, 376-384 (2010).

146) T. Perry, J. A. McKenzie and P. Batterham: Insect Biochem. Mol. Biol. 37, 184-188 (2007).

147) J. Somers, J. Nguyen, C. Lumb, P. Battherham and T. Perry: Insect Biochem. Mol. Biol. 64, 116-127 (2015).

148) J.-Z. Zhao, Y.-X. Li, H. L. Collins, L. Gusukuma-Minuto, R. F. L. Mau, G. D. Thompson and A. M. Shelton: J. Econ. Entomol. 95, 430436 (2002).

149) S. W. Baxter, M. Chen, A. Dawson, J.-Z. Zhao, H. Vogel, A. M. Shelton, D. G. Heckel and C. D. Jiggins: PLoS Genet. 6, e1000802 (2010).

150) A. M. Puinean, S. J. Lansdell, T. Collins, P. Bielza and N. S. Millar: J. Neurochem. 124, 590-601 (2013).

151) J. C. Hsu, H. T. Feng, W. J. Wu, S. M. Geib, C. H. Mao and J. Vontas: Insect Biochem. Mol. Biol. 42, 806-815 (2012).

152) S. J. Landsell and N. S. Millar: J. Neurochem. 90, 479-489 (2004).

153) D. B. Sattelle, I. D. Harrow, J. A. David, M. Pelhate, J. J. Callec, J. I. Gepner and L. M. Hall: J. Exp. Biol. 118, 37-52 (1985).

154) V. Raymond Delpech, M. Ihara, C. Coddou, K. Matsuda and D. B. Sattelle: Invert. Neurosci. 5, 29-35 (2003).

155) K. Nagata, Y. Iwanaga, T. Shono and T. Narahashi: Pestic. Biochem. Physiol. 59, 119-128 (1997).

156) S.-J. Lee, M. Tomizawa and J. E. Casida: J. Agric. Food Chem. 51, 2646-2652 (2003)

157) S.-J. Lee, P. Caboni, M. Tomizawa and J. E. Casida: J. Agric. Food Chem. 52, 95-98 (2004).

158) T. R. Roberts and D. H. Hutson: "In Metabolic Pathways of Agrochemicals, Part 2: Insecticides and Fungicides" ed. by T. R. Roberts, D. H. Hutson, P. W. Lee, P. H. Nicholls and J. R. Plimmer, The Royal Society of Chemistry: Cambridge U.K. pp. 129-133, 1999. 